\title{
Laboratórios on-line em aulas de Física no Ensino Médio: proposta de uso em sequências didáticas investigativas ${ }^{+}$
}

\author{
Juarez Bento Silva ${ }^{1}$ \\ Simone Meister Sommer Bilessimo ${ }^{1}$ \\ Universidade Federal de Santa Catarina \\ Florianópolis - SC \\ Ladislei Marques Felipe Castro ${ }^{1}$ \\ Mestranda - Universidade Federal de Santa Catarina \\ Schirley Aparecida de Alano Scheffer ${ }^{1}$ \\ Escola de Educação Básica Rubens de Arruda Ramos \\ Criciuma - SC
}

\section{Resumo}

Este documento explorou os laboratórios on-line e suas potencialidades, para atividades práticas em disciplina de Física no Ensino Médio. Os laboratórios on-line podem apoiar as atividades experimentais, que se constituem em um dos aspectos-chave nos processos de ensino e de aprendizagem das ciências. A pesquisa, aplicada, de abordagem quantitativa utilizou como estratégia um estudo de caso. Participaram da pesquisa, realizada em 2019, 179 alunos, de 10 turmas de $1^{\circ}, 2^{\circ}$ e $3^{\circ}$ anos, da disciplina de Física, de duas escolas públicas estaduais, em Criciuma/SC. Para apoiar as atividades e disponibilizar os conteúdos didáticos foram implementadas sequências didáticas investigativas (SDI), que foram disponibilizadas em um ambiente virtual de aprendizagem (AVEA). As SDI foram apoiadas por laboratórios on-line, para realização das atividades práticas. Para a coleta de dados foram aplicados três questionários: Perfil do aluno, Experiência de Ensino e Enquete Vocacional. O questionário experiência de ensino foi respondido pela totalidade dos alunos e o escore médio de Likert, obtido para os 20 itens do questionário foi de 4,51, demonstrando uma atitude

\footnotetext{
${ }^{+}$Didactic investigative sequences with use of online laboratories: proposal for High School Physics classes

* Recebido: 13 de agosto de 2020.

Aceito: 14 de julho de 2021.

${ }^{1}$ E-mails: juarez.silva@ufsc.br; simone.bilessimo@ufsc.br; ladislei.castro@gmail.com; schirleyscheffer@gmail.com
} 
muito positiva dos alunos em relação a utilização dos recursos tecnológicos utilizados, a saber o AVEA e os laboratórios remotos. Dados obtidos no questionário Perfil do Aluno indicaram que 86,39\% dos alunos declararam intenção em cursar o ensino superior, porém, apenas 2,96\% demonstraram interesse pelas carreiras nas áreas das Ciências Exatas (Matemática, Física, Química e Biologia). E no instrumento Enquete Profissional, os cursos da área de Engenharia e Tecnologia foram a $4^{a}$ opção com maior pontuação e Ciências Exatas a $7^{a}$ para um total de 8 possibilidades. São resultados que nos permitem refletir sobre o potencial das tecnologias digitais e seu potencial de contribuição para a educação, porém, também apontaram grande desinteresse dos alunos pesquisados em relação a ingressar em carreiras tecnológicas ou na área das ciências exatas.

Palavras-chave: Laboratórios On-line; Ensino de Física; Tecnologia Educacional; Educação Básica; Sequências Didáticas Investigativas.

\begin{abstract}
This document explored the online laboratories and their potential, for practical activities in the discipline of Physics in High School. Online laboratories can support experimental activities, which are one of the key aspects of science teaching and learning processes. The research, applied, with a quantitative approach, used a case study as a strategy. 179 students participated in the research, carried out in 2019, from 10 classes of 1st, 2nd and 3rd years, in the discipline of Physics, from two state public schools, in Criciuma / SC. To support the activities and make the didactic content available, investigative didactic sequences (SDI) were implemented, which were made available in a virtual learning environment (AVEA). The SDI were supported by online laboratories to carry out practical activities. For data collection, three questionnaires were applied: Student profile, Teaching Experience and Vocational Survey. The teaching experience questionnaire was answered by all students and the average Likert score obtained for the 20 items of the questionnaire was 4.51, demonstrating a very positive attitude of students towards the use of the technological resources used, namely the AVEA and remote labs. Data obtained from the Student Profile questionnaire indicated that $86.39 \%$ of students declared their intention to attend higher education, however, only 2.96\% showed interest in careers in the areas of Exact Sciences (Mathematics, Physics, Chemistry
\end{abstract}


and Biology). And in the Professional Poll instrument, courses in the area of Engineering and Technology were the 4th option with the highest score and Exact Sciences the 7th for a total of 8 possibilities. These are results that allow us to reflect on the potential of digital technologies and their potential to contribute to education, however, they also pointed out a great lack of interest among the researched students in relation to entering technological careers or in the area of exact sciences.

Keywords: Online Laboratories; Physics Teaching; Educational Technology; High School; Didactic Investigative Sequences.

\section{Introdução}

O progresso econômico e social do futuro de uma nação passa pela transformação tecnológica em todas as áreas do conhecimento. Transformação esta que coloca diversos desafios, em cada setor, impactando nestes, por exemplo no mercado de trabalho e na educação. Pois, essa transformação tecnológica, que pode ser entendida como uma revolução digital, implica, entre outras coisas, na criação de novas oportunidades de trabalho. Em um mercado de trabalho que cada vez mais exige trabalhadores com perfis STEM (Ciência, Tecnologia, Engenharia e Matemática). De acordo com o Fórum Econômico Mundial, em 2013, a China apresentava 40\% de graduados nas áreas STEM e 45\% de ciências humanas, ciências sociais, direito e educação, enquanto para a Índia os números eram de $35 \%$ e $53 \%$, respectivamente. Até 2030, se as taxas de graduação das áreas STEM continuarem nesses níveis, a China e a Índia responderão por mais de $60 \%$ dos graduados nestas áreas entre os países membros da Organização para a Cooperação e Desenvolvimento Econômico (OCDE). Enquanto que Europa e Estados Unidos (UE) responderão com 8\% e 4\% dos graduados, respectivamente. O Fórum Econômico Mundial informou que a China tinha 4,7 milhões de recém-formados em STEM em 2016. A Índia, outra potência acadêmica, teve 2,6 milhões de novos formados em STEM, enquanto os EUA tinham 568.000 e Rússia 561.000. A Tabela 01 apresenta os países com mais graduados em ciências, tecnologia, engenharia e matemática em 2016, segundo o Human Capital Index 2016.

Pode-se observar na Tabela 01 que uma parcela significativa do total de graduados, no mundo, nas áreas STEM, é produzida por um número relativamente pequeno de países, não surpreendentemente aqueles com populações maiores. Porém, esta tendência não se aplica ao Brasil, que ocupa a posição de $5^{\circ}$ maior país em população, ficando abaixo apenas da China, Índia, Estados Unidos e Indonésia, e não aparece nesta lista. Segundo o relatório Education at a Glance 2018, o Brasil está entre os países com menor porcentual de graduados nas áreas de STEM. E constitui-se em desafio, atrair bons e mais estudantes para essa área, pois este é um dos caminhos para desenvolver a economia de um país. Segundo o relatório, entre os graduados brasileiros, apenas $17 \%$ são dos cursos da área de STEM, enquanto que a 
média dos países ricos é de 24\%. Os dados do Quadro 01, foram obtidos do Censo da Educação Superior 2018 (BRASIL.INEP, 2019a).

Tabela 01 - Países com mais graduados em ciências, tecnologia, engenharia e matemática em 2016.

\begin{tabular}{l|r}
\hline \multicolumn{1}{c|}{ PAÍSES } & \multicolumn{1}{c}{$\mathbf{N}^{\mathbf{0}}$ EGRESSOS } \\
\hline CHINA & 4.666 .000 \\
\hline ÍNDIA & 2.575 .000 \\
\hline ESTADOS UNIDOS & 568.000 \\
\hline FEDERAÇÃO RUSSA & 561.000 \\
\hline REPÚBLICA DO IRAN & 335.000 \\
\hline INDONÉSIA & 206.000 \\
\hline JAPÃO & 195.000 \\
\hline OUTROS PAÍSES & 3.372 .000 \\
\hline TOTAL & 12.478 .000 \\
\hline
\end{tabular}

Fonte: Human Capital Index (2016).

Quadro 01 - Ingressantes e concluintes em cursos de graduação.

\begin{tabular}{|l|c|c|c|c|c|c|c|c|c|c|}
\hline \multirow{2}{*}{ Área Geral do Curso } & \multicolumn{3}{|c|}{ Ingressantes para cada 10.000 habitantes } & \multicolumn{3}{c|}{ Concluintes para cada 10.000 habitantes } \\
\cline { 2 - 12 } & Média & 2015 & 2016 & 2017 & 2018 & Média & 2015 & 2016 & 2017 & 2018 \\
\hline Educação & 30,3 & 26,0 & 29,3 & 31,6 & 34,2 & 12,0 & 11,7 & 11,7 & 12,3 & 12,1 \\
\hline Artes e Humanidades & 3,4 & 3,3 & 3,2 & 3,4 & 3,8 & 1,5 & 1,4 & 1,5 & 1,5 & 1,6 \\
\hline $\begin{array}{l}\text { Ciências Sociais, Jornalismo } \\
\text { e Informação }\end{array}$ & 6,9 & 6,7 & 6,6 & 7,1 & 7,3 & 2,6 & 2,3 & 2,5 & 2,7 & 3,0 \\
\hline $\begin{array}{l}\text { Negócios, Administração e } \\
\text { Direito }\end{array}$ & 51,8 & 48,8 & 49,3 & 53,2 & 55,9 & 21,1 & 22,0 & 21,2 & 20,4 & 20,8 \\
\hline $\begin{array}{l}\text { Ciências Naturais, } \\
\text { Matemática e Estatística }\end{array}$ & $\mathbf{1 , 8}$ & $\mathbf{1 , 9}$ & $\mathbf{1 , 8}$ & $\mathbf{1 , 8}$ & $\mathbf{1 , 8}$ & $\mathbf{0 , 8}$ & $\mathbf{0 , 7}$ & $\mathbf{0 , 7}$ & $\mathbf{0 , 8}$ & $\mathbf{0 , 8}$ \\
\hline Computação e TIC & 7,3 & 6,9 & 6,9 & 7,3 & 7,9 & 2,1 & 2,2 & 2,2 & 2,0 & 2,1 \\
\hline $\begin{array}{l}\text { Engenharia, Produção e } \\
\text { Construção }\end{array}$ & 18,6 & 21,2 & 18,8 & 17,7 & 16,8 & 6,8 & 5,6 & 6,4 & 7,1 & 7,9 \\
\hline Agricultura, Veterinária, etc. & 3,6 & 3,4 & 3,4 & 3,6 & 4,0 & 1,3 & 1,1 & 1,2 & 1,3 & 1,5 \\
\hline Saúde e Bem-Estar & 24,6 & 21,0 & 22,6 & 26,0 & 28,8 & 8,8 & 8,1 & 8,3 & 9,0 & 9,9 \\
\hline Serviços & 3,7 & 3,2 & 3,1 & 3,8 & 4,6 & 1,4 & 1,3 & 1,5 & 1,3 & 1,4 \\
\hline
\end{tabular}

Fonte: MEC/INEP (2019).

Os dados apresentados no Quadro 01 corroboram o relatório Education at a Glance 2018. O quadro mostra número de ingressantes e concluintes em cursos de graduação no Brasil, no período 2015 a 2018. Os números apresentados abaixo referem-se ao número de ingressos e de concluintes, em cursos de graduação para cada 10.000 habitantes, segundo a 
área geral do curso (MEC/INEP, 2019a).

Vamos nos fixar na área das Ciências Naturais, Matemática e Estatística, de maior interesse nesta publicação. Nesta o número médio de ingressantes, no triênio apresentado é de 1,8 ingressantes e 0,8 concluintes para cada 10.000 habitantes. Para as duas situações apresentadas, é o menor número entre todas as áreas. Em relação ao valor médio total enquanto que a área de "Negócios, Administração e Direito" representa 34\% do total de ingressantes e $36 \%$ do total de concluintes, a área de "Ciências Naturais, Matemática e Estatística", representa 1\%, tanto para ingressantes, quanto para concluintes. As áreas de "Engenharia, Produção e Construção" e "Computação e TIC", apresentam percentuais de 12\% e $5 \%$ para ingressantes e $12 \%$ e $4 \%$ para concluintes, respectivamente.

Mais especificamente nos cursos de graduação em Física: os cursos de bacharelados de Física em 2018 apresentaram 7.414 matrículas e 768 concluintes, em relação a licenciatura foram, no mesmo período 28.732 inscritos e 2.532. Números muitos distantes de cursos de graduação em Administração e Direito que apresentaram 1.125.284 e 863.101 para matrículas e 202.784 e 126.176 para concluintes, respectivamente. Ainda que apresentam número expressivamente menores que cursos nas áreas de Administração e Direito, também outro dado chama muito a atenção, pois, enquanto cursos de Administração e Direito, apresentaram respectivamente $18 \%$ e $15 \%$, na relação concluintes/matriculados, os cursos de bacharelado e licenciatura em Física apresentam percentuais de 10\% e 9\%, respectivamente. Ou seja, além de uma procura significativamente menor, a taxa de sucesso nestes também é bem menor.

A falta de interesse da população jovem pelas áreas das ciências, engenharias e matemática, é uma preocupação em nível mundial, inclusive foi manifestada pela UNESCO. Que neste sentido, argumentou que o crescimento econômico futuro e o progresso social, dentro das perspectivas da sociedade atual, dependem de educação e inovação, devendo-se incentivar a busca dos estudantes pelas áreas de STEM (GRIMUS; EBNER, 2016). Ou seja, que fomentar a identidade dos estudantes com as áreas de ciências, tecnologia, engenharia e matemática irá permitir maior adesão a carreiras associadas a tais disciplinas/áreas (MARTIN-HANSEN, 2018).

Os motivos que levam os jovens a não se motivarem pelas disciplinas e carreiras nas áreas científicas e tecnológicas, são diversos, tal como, a impopularidade das disciplinas STEM, pois, alguns destes acham a matemática e as ciências chatas ou até muito difíceis. Porém, neste documento vamos focar em dois pontos: a necessidade de ambientes mais atrativos para o ensino e a aprendizagem, na educação básica e as carências de infraestrutura, principalmente, nas escolas brasileiras de educação básica da rede pública.

Em relação ao primeiro, presenciamos diariamente que as tecnologias digitais evoluem numa velocidade vertiginosa, em um ritmo em constante aceleração. Tecnologias estas que são parte integrante da sociedade em que vivemos e que impactam no modo de vida das pessoas. Percebemos que smartphones, notebooks e uma infinidade de aparatos computacionais que rodeiam nossas atividades, necessitam alcançar o âmbito educacional. A 
inserção destas tecnologias, no contexto educacional, pode redesenhar a educação e criar novas e interessantes oportunidades de ensino e de aprendizagem. Por exemplo, lançando mão do uso de dispositivos móveis e Internet no contexto educacional. A integração das tecnologias digitais, no contexto educacional, pode oportunizar a criação de ambientes compatíveis, não antagônico, com a forma como as crianças, jovens e adolescentes aprendem. Por exemplo, promover o acesso a novas ferramentas no ensino de Física permitirá certamente ampliará a motivação dos estudantes para esta disciplina e, quem sabe, melhorar as possibilidades de adesão de estudantes a carreiras vinculadas às áreas científicas e tecnológicas. Outro fator importante, relacionado à integração das tecnologias digitais aos processos de ensino e de aprendizagem, é que estas permitem estender não só a sala de aula, como também a escola. Pois, não limitam estes processos ao tempo e ao espaço da sala de aulas.

$\mathrm{O}$ segundo ponto está relacionado às carências de infraestrutura das escolas de educação básica no Brasil, é importante destacar a disponibilidade de laboratórios de ciências, para apoiar as disciplinas nas áreas STEM. Segundo o Censo Escolar MEC/INEP 2018, apenas $11 \%$ das escolas no Brasil (8\% públicas e 19\% privadas) dispunham de laboratórios de ciências (MEC/INEP, 2019b). Esta carência laboratorial impacta negativamente na possibilidade de realização de atividades experimentais. Ocorre que a realização de atividades experimentais é um aspecto muito importante nos processos de ensino e de aprendizagem de ciências. Tanto pelo apoio a fundamentação teórica que pode proporcionar aos alunos quanto pelo desenvolvimento de certas habilidades para as quais o trabalho experimental é fundamental. Existem argumentos favoráveis às práticas laboratoriais relacionados ao seu valor para favorecer a construção de conhecimento conceitual e processual, aspectos relacionados à metodologia científica, promoção de capacidades de raciocínio, pensamento crítico e criativo e objetividade e desconfiança diante de julgamentos de valor que carecem da evidência necessária (HODSON, 2000; WELLINGTON, 1998).

Em relação às atividades experimentais em Física, área pesquisada neste documento, citam-se aqui os objetivos de instrução laboratorial, de acordo com a Associação Americana de Professores de Física AAPT. Para a AAPT (1998), o objetivo da instrução de laboratório é apoiar os alunos:

- na realização de experiências significativas através de processos experimentais;

- na aprendizagem de conceitos básicos;

- no desenvolvimento de habilidades, bem como na aquisição das ferramentas básicas necessárias para a física experimental e a análise de dados;

- na compreensão do papel da observação direta na física e distinguir entre inferências baseadas na teoria e nos resultados experimentais e inferências baseadas em resultados dos experimentos.

Observa-se pelos dados apresentados que as instituições de ensino de educação básica, em geral, apresentam uma dotação adequada nos laboratórios de ciências, 
principalmente para a área de Física. Este é um dos motivos, para a falta de práticas experimentais mínimas. E assim a dimensão teórica é priorizada no ensino, deixando de lado a dimensão prática. Deve-se ter em conta que a atividade experimental faz muito mais do que apoiar aulas teóricas em qualquer área do conhecimento. Seu papel é muito importante, pois desperta e desenvolve a curiosidade dos alunos, ajudando-os a resolver problemas e a explicar e entender os fenômenos com os quais interagem no dia a dia. Certamente uma aula de Física teórica, de mãos dadas com um ensino experimental criativo e contínuo, pode contribuir para o desenvolvimento de algumas das habilidades exigidas pela construção do conhecimento científico. A respeito da importância da experimentação para o ensino de Física, tem-se que "a utilização de experimentos práticos nas aulas de áreas STEM facilita as capacidades dos alunos de aplicar seus conhecimentos, trabalhar de forma colaborativa, controlar equipamento, analisar os dados de medição, compará-los com as previsões teóricas e escrever relatórios" (NAFALSKI; MACHOTKA; NEDIC, 2011, p185).

Dentro da perspectiva que existe a necessidade de ambientes mais atrativos para o ensino e a aprendizagem, na educação básica e que as escolas da educação básica carecem de infraestruturas laboratoriais e tecnológicas, este documento apresenta uma proposta de utilização de laboratórios on-line, para apoiar o ensino de Física. A elaboração e a construção do material didático foram inspiradas na Aprendizagem Baseada em Investigação (ABI), disponibilizada em Ambiente Virtual de Ensino e Aprendizagem (AVEA). A ABI, também conhecida por inquiry, tem como seu precursor o filósofo norte-americano John Dewey (1852-1959), que se opunha a uma educação predominantemente tradicional, voltada à memorização. Para Dewey, "o conhecimento é uma atividade dirigida que não tem um fim em si mesmo, mas está voltada para a experiência" (ARANHA, 1997, p. 170). Assim, foi definida uma sequência didática investigativa, cujas atividades foram organizadas em 5 etapas: Orientação, Contextualização, Investigação, Discussão e Conclusão.

Os laboratórios on-line podem ser utilizados na Educação Básica, a fim de servir como ferramenta de apoio ao ensino e aprendizagem nas disciplinas STEM, especialmente tocante aos estudos de Física, com possibilidade de desenvolvimento de atividades práticas ou experimentais tanto dentro quanto fora da sala de aula. Conforme Silva (2018, p. 113), "os laboratórios on-line vem apresentando grandes avanços no campo tecnológico, quando se trata de automação de experimentos de laboratórios didáticos", voltados para a oportunidade de acessos remotos a estudantes de cursos que não oferecem laboratórios físicos nas instituições de ensino, seja por restrições de segurança, orçamento, tempo ou capacidade.

Nos laboratórios on-line, os parâmetros de investigação podem ser manipulados e os efeitos dessa manipulação são observados para obter informações sobre a relação entre variáveis no modelo conceitual subjacente a estes laboratórios (DE JONG; SOTIRIOU; GILLET, 2014). Nessa perspectiva, os laboratórios on-line configuram-se com uma opção viável para suprir a deficiência de laboratórios físicos nas escolas, tendo em vista a ampliação progressiva, e aparentemente irreversível, das Tecnologias da Informação e Comunicação. 
Estes laboratórios pretendem oferecer experiência similar à experimentação presencial, com acesso por meio da internet, sendo que há estudos apontando vantagens para a aprendizagem associada à utilização das referidas ferramentas on-line (MUJKANOVIC et al., 2015; NMC, 2018).

Segundo Zutin et al. (2010), há duas modalidades principais de laboratórios on-line: simulações de software e laboratórios formados por equipamentos reais de hardware. As simulações on-line de software denominam-se laboratórios virtuais. Por sua vez, os laboratórios de acesso on-line constituídos por maquinário real, mas distante do aluno, podem ser intitulados de laboratórios remotos. Como terceira possibilidade, há os laboratórios híbridos, os quais mesclam as duas primeiras categorias supracitadas. De modo similar, SILVA et al. (2020) argumentam que os laboratórios virtuais permitem a reprodução de qualquer experimento, sem restrições e experimentos reais. Já os laboratórios remotos, tratamse de forma de interação com o experimento mediada por TIC. Desse modo, no laboratório remoto, o aluno manipula materiais e equipamentos reais em local diverso do qual se encontra (SILVA et al., 2020). O controle de hardware dá-se de modo remoto, com experimentos e as instalações reais.

A Fig. 01 exibe os tipos de laboratórios on-line, comparando-os com a modalidade convencional (laboratório hands-on).

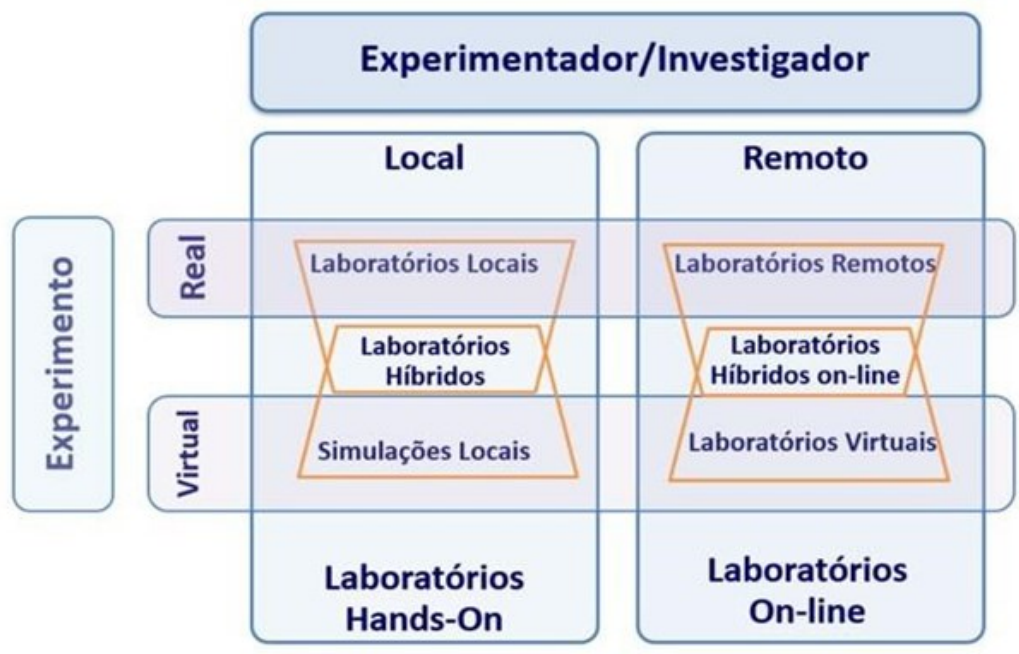

Fig. 1 - Classificação dos laboratórios on-line.

Fonte: Zutin et al. (2010)

O laboratório remoto ajuda o estudante a obter informações através da Internet buscando-as diretamente no mundo físico e permite o acesso a recursos que às vezes as instituições não possuem, além disso, os laboratórios remotos se constituem em uma ferramenta útil, em termos financeiros, na medida em que podem ser compartilhados com diversas instituições de ensino e possibilitam que um grande número de usuários os acessem (CARNEGIE MELLON UNIVERSITY, 2000). Os laboratórios remotos podem tornar a 
aprendizagem mais flexível em relação ao tempo, local e ao ritmo do aluno, podendo a prática ser realizada de acordo com a disponibilidade de horário, além de promover a sua autoaprendizagem (GALÁN et al., 2018). Além da flexibilidade de local, não há limitação quanto ao tempo utilizado junto ao experimento, havendo disponibilidade de horários (ZUTIN et al., 2010; CORREIA, 2018; LORO, 2018). Contribui-se, ademais, com a liberdade de aprendizagem dos alunos, bem como oportuniza conhecimentos transversais sobre as TIC (LORO, 2018).

$\mathrm{O}$ ato de acessar os recursos de um laboratório remoto para realização de uma atividade prática pode ser denominado experimentação. Segundo a Carnegie Mellon University (2000), a execução de experimentos de um local remoto é chamada de experimentação remota. Esta experimentação permite ao usuário interação com o mundo real, através de controle eletrônico e sistemas de monitoramento e controle, acessados por dispositivos computacionais.

Embora seja um assunto relativamente novo em termos de pesquisa educacional, os laboratórios remotos não são um recurso muito recente. O SBBT (Second Best to Being There), na Universidade de Oregon State e colocado em operação em 1995, é reconhecido como o primeiro laboratório remoto do mundo. O SBBT teve por objetivo possibilitar que alunos controlassem remotamente um braço robótico. O recurso tecnológico foi utilizado na disciplina de Engenharia de Controle (BOHUS et al. 1995).

Por fim, Loro (2018) distingue quatro formas de laboratórios, quais sejam: simulador, laboratório virtual, laboratório remoto e laboratório presencial. Uma comparação entre as vantagens e desvantagens das referidas espécies laboratoriais encontram-se no Quadro 02.

Quadro 02 - Características dos diferentes tipos de laboratórios.

\begin{tabular}{|l|c|c|c|c|}
\hline \multicolumn{1}{|c|}{ Descrição } & Simulador & $\begin{array}{c}\text { Laboratório } \\
\text { virtual }\end{array}$ & $\begin{array}{c}\text { Laboratório } \\
\text { Remoto }\end{array}$ & $\begin{array}{c}\text { Laboratório } \\
\text { Presencial }\end{array}$ \\
\hline Uso de equipamentos Reais & Não & Não & Sim & Sim \\
\hline Resultados & Modelados & Modelados & Reais & Reais \\
\hline Conexão com a Internet & Não & Sim & Sim & Não \\
\hline Localização & $\begin{array}{c}\text { Virtual } \\
(\mathrm{PC})\end{array}$ & $\begin{array}{c}\text { Virtual } \\
\text { (Web) }\end{array}$ & $\begin{array}{c}\text { Virtual (Web); } \\
\text { Físico (limita do) }\end{array}$ & $\begin{array}{c}\text { Físico (aula } \\
\text { preparada) }\end{array}$ \\
\hline Problemas de versões & Sim & Não & Não & Não \\
\hline $\begin{array}{l}\text { Interação com o } \\
\text { monitor/tutor }\end{array}$ & Assíncrona & Assíncrona & Assíncrona & Síncrona \\
\hline Interação entre pares & Não & $\begin{array}{c}\text { Em geral } \\
\text { não }\end{array}$ & Em geral não & Sim \\
\hline Disponibilidade & $\begin{array}{c}\text { A qualquer } \\
\text { momento }\end{array}$ & $\begin{array}{c}\text { A qualquer } \\
\text { momento }\end{array}$ & $\begin{array}{c}\text { A qualquer } \\
\text { momento }\end{array}$ & $\begin{array}{c}\text { Em geral } \\
\text { limita da }\end{array}$ \\
\hline
\end{tabular}




\begin{tabular}{|l|c|c|c|c|}
\hline Custo & $\begin{array}{c}\text { Versões } \\
\text { gratuitas ou } \\
\text { pagas }\end{array}$ & $\begin{array}{c}\text { Versões } \\
\text { gratuitas ou } \\
\text { pagas }\end{array}$ & $\begin{array}{c}\text { Versões gratuitas } \\
\text { ou pagas }\end{array}$ & $\begin{array}{c}\text { Custo de } \\
\text { implantação }\end{array}$ \\
\hline Interface & $\begin{array}{c}\text { Abstração } \\
\text { em geral }\end{array}$ & $\begin{array}{c}\text { Abstração } \\
\text { ou emulada }\end{array}$ & $\begin{array}{c}\text { Abstração, } \\
\text { emulada ou real }\end{array}$ & Real \\
\hline Segurança do ambiente & Total & Total & $\begin{array}{c}\text { Total para os } \\
\text { usuários, média/ } \\
\text { alta para } \\
\text { equipamentos. }\end{array}$ & $\begin{array}{c}\text { Nenhuma } \\
\text { especial. }\end{array}$ \\
\hline
\end{tabular}

Fonte: Adaptado de LORO (2018).

Este documento explora a utilização de laboratórios on-line para utilização em atividades experimentais em disciplina de Física, no Ensino Médio. Para dar suporte ao uso dos laboratórios on-line, os conteúdos didáticos foram elaborados na forma de sequencias didáticas investigativas e disponibilizados em AVEA. Para investigar como os alunos perceberam a integração dos recursos tecnológicos na disciplina, optou-se por uma abordagem quantitativa, sendo utilizados três instrumentos, na forma de questionários on-line. Os instrumentos aplicados tiveram dois objetivos, o primeiro foi identificar as barreiras percebidas e testar o modelo proposto considerando o escopo da utilização de laboratórios online, para ajudar a melhorar as práticas educacionais em disciplinas de Física. No documento argumentamos sobre a falta de interesse da população jovem pelas áreas das ciências, engenharias e matemática, que é uma preocupação em nível mundial, inclusive foi manifestada pela UNESCO. Assim, o segundo objetivo foi buscar perceber se este fato ocorreu nas turmas que participaram da pesquisa. Assim, os instrumentos aplicados tiveram como objetivo fornecer respostas para as seguintes perguntas pesquisadas:

- Como os alunos percebem o uso dos laboratórios on-line na disciplina de Física?

- Os estudantes das turmas pesquisadas seguem os dados apresentados, em nível nacional, e não demostram interesse pelas áreas científicas e tecnológicas?

\section{Metodologia}

Este estudo teve como objetivo explorar a utilização de laboratórios on-line como recurso para utilização em atividades experimentais em disciplina de Física, no Ensino Médio. A Fig. 02 apresenta as fases cumpridas para realização da pesquisa. 


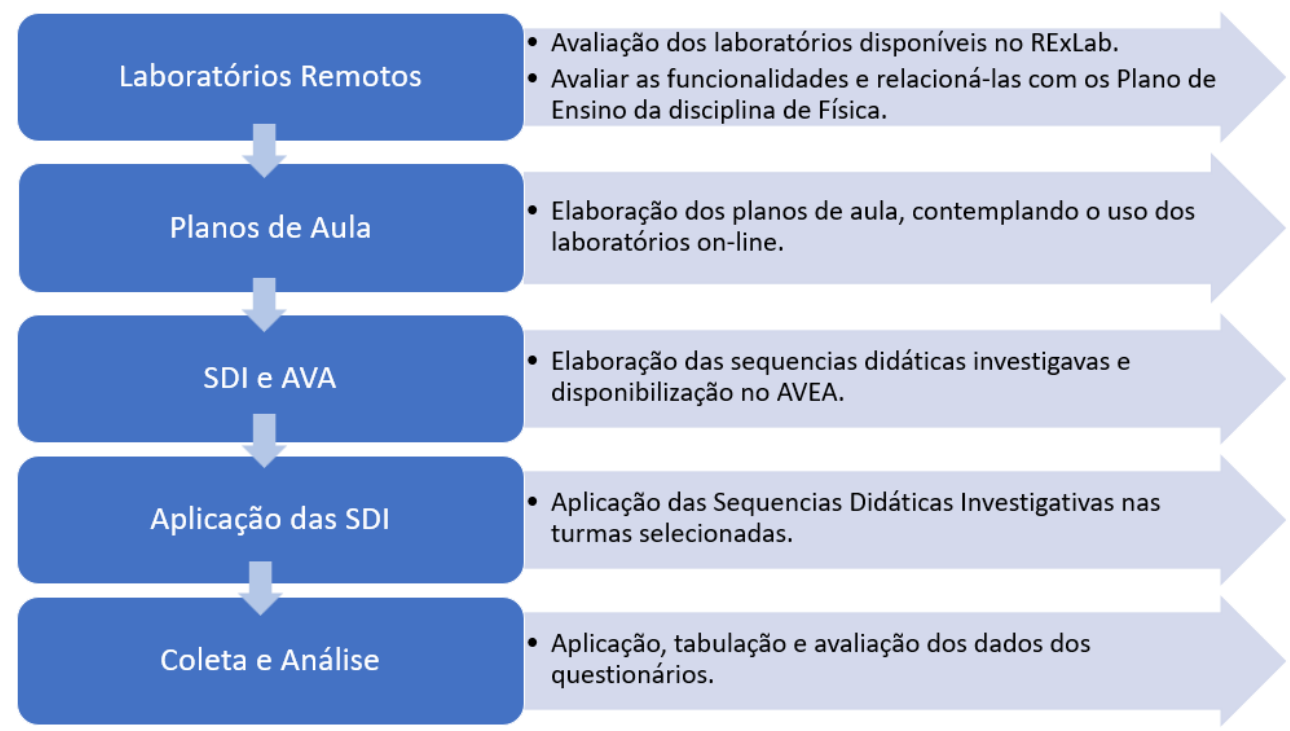

Fig. 2 - Fases de desenvolvimento da pesquisa.

Fonte: Autores (2020).

\section{II.1 Participantes}

Participaram do estudo alunos de duas escolas estaduais da rede pública de Santa Catarina, situadas na cidade de Criciúma. A definição das escolas e das turmas esteve relacionada ao fato de uma das autoras do trabalho atuar como docente, na disciplina de Física, nas duas escolas. Foram definidas 10 (dez) turmas e 179 alunos das três séries do Ensino Médio, pela docente e coautora desta pesquisa. A professora é Licenciada em Física e Química.

\section{II.2 Laboratórios Remotos e construção dos planos de aula}

As aplicações ocorreram no Ensino Médio. Para o primeiro ano o laboratório remoto escolhido foi o Plano Inclinado, para o segundo ano foi o de Condução de Calor em Barras Metálicas e para o terceiro foram utilizados dois laboratórios: o Painel Elétrico CC e o Painel Elétrico CA, todos disponibilizados, com acesso livre, na Plataforma RELLE (http://relle.ufsc.br/) do Laboratório de Experimentação Remota (RExLab) da Universidade Federal de Santa Catarina

Os laboratórios remotos foram selecionados a partir de conteúdos específicos, que constam no plano de ensino da disciplina, um para cada ano correspondente: Queda livre para as turmas do $1^{\circ}$; Calor e sua propagação para as turmas do $2^{\circ}$ e eletrodinâmica (associação de resistores) para as turmas do $3^{\circ}$ ano. A escolha dos conteúdos para elaboração dos planos de aulas seguiu o fluxo estabelecido no plano de ensino da professora. A fim de manter o curso normal da disciplina e não tratar a utilização dos recursos digitais, como uma ação isolada ou extraoficial, pois, isso poderia trazer prejuízos à avaliação pretendida. 


\section{II.3 Sequências didáticas investigativas e AVEA}

$\mathrm{Na}$ literatura sobre educação científica se faz referência a "investigação" para designar pelo menos três categorias de diferentes atividades, porém inter-relacionadas:

- a que fazem os cientistas (investigar fenômenos científicos mediante o uso de métodos para explicar aspectos do mundo físico);

- como os alunos aprendem (seguindo perguntas científicas e participando de experimentos científicos que imitam as práticas e processos usados pelos cientistas); e,

- uma pedagogia, ou estratégia de ensino, adotada por professores de ciências (planejando e facilitando atividades de aprendizagem que permitam aos alunos observar, experimentar e revisar o que é conhecido à luz das evidências) (MINNER et al., 2010).

A aprendizagem de ciências baseada em investigação, por outro lado, envolve o aluno fazendo perguntas de pesquisa, gerando uma hipótese, projetando experimentos para verificá-las, construindo e analisando argumentos baseados em evidências, reconhecendo explicações alternativas e comunicando argumentos científicos (TAMIR, 1985).

A aprendizagem baseada em investigação busca envolver os alunos em um processo de descoberta científica. Do ponto de vista pedagógico, o processo científico é dividido em unidades menores, conectadas logicamente, que orientam os alunos e chamam a atenção para características importantes do pensamento científico. Essas unidades individuais são chamadas de fases de investigação e seu conjunto de conexões forma um ciclo de investigação. A maneira como um ciclo é apresentado geralmente sugere uma sequência ordenada de fases. No entanto, a aprendizagem baseada em investigação não é um processo linear uniforme e prescrito. As conexões entre as fases podem variar dependendo do contexto.

Para a presente pesquisa foi aplicado o modelo utilizado pelo projeto Go-Lab ${ }^{2}$ e que vem sendo aplicado no Programa InTecEdu, desenvolvido pelo RExLab. O modelo é composto por cinco fases gerais de pesquisa: Orientação, Conceitualização, investigação, conclusão e discussão, conforme mostrado da Fig. 3.

Algumas fases da investigação podem incluir vários segmentos, mas todas as fases do processo de aprendizagem por investigação estão intimamente ligadas entre si e fornecem uma estrutura destinada a aumentar a eficiência das atividades de aprendizagem conduzidas com laboratórios on-line e ferramentas adicionais de aprendizagem.

\footnotetext{
2 Global On-line Science Labs for Inquiry Learning at School é um projeto europeu cofinanciado pela Comissão Europeia, une 19 organizações de doze países, entre as quais o NUCLIO - Núcleo Interactivo de Astronomia. O Projeto visa promover a aprendizagem baseada em investigação com a utilização de laboratórios on-line a fim de

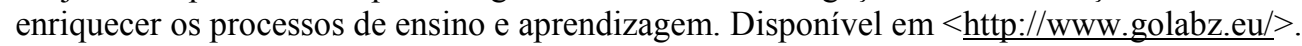




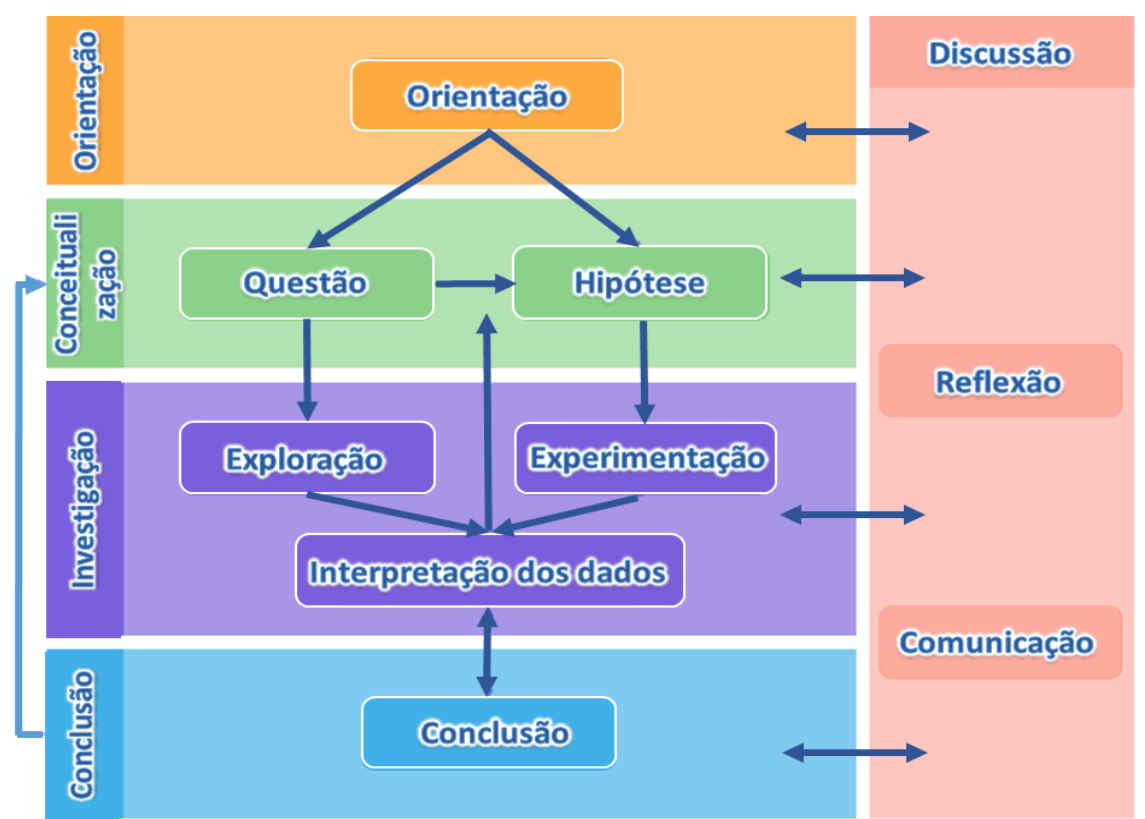

Fig. 3 - Modelo de aprendizagem por investigação do Projeto Go-Lab.

Fonte: Adaptado de Margus Pedaste et. al. (2015).

Nas duas primeiras fases do ciclo (orientação e conceituação), os alunos têm a oportunidade de coletar informações sobre uma questão de pesquisa, tomar notas e construir hipóteses e perguntas que desejam pesquisar. Os professores podem fornecer ferramentas apropriadas (como modelos de mapas conceituais, software de pesquisa, bloco de notas, construtor de hipóteses, etc.) para ajudar os alunos a trabalhar sozinhos nos espaços de consulta de aprendizado.

A interação real com o laboratório on-line ocorre na terceira fase, a investigação (que inclui atividades de exploração, experimentação e interpretação de dados). Nesta fase, os alunos coletam dados específicos e verificam se uma hipótese está correta, realizando experiências on-line personalizadas. Além disso, os alunos podem compilar os resultados das experiências e realizar uma interpretação guiada dos dados coletados.

Durante as duas últimas fases do processo de aprendizagem da investigação (conclusão e discussão), os alunos deverão aprender a redigir explicações científicas buscando vincular suas hipóteses às evidências coletadas durante a fase de pesquisa. Além disso, estarão refletindo sobre seus processos e resultados de aprendizagem, comparando e discutindo-os com outros alunos. Os professores podem avaliar os resultados de aprendizagem de seus alunos e definir etapas adicionais para as próximas aulas.

O AVEA do Programa InTecEdu está baseado no Moodle. Assim, a docente previamente apresentou o ambiente aos alunos, efetuou os cadastros e estes puderam acessar um curso teste, a fim de, familiarizar-se com a ferramenta. 


\section{II.4 Aplicação das sequências didáticas}

A aplicação das sequências didáticas foi consonante com os temas escolhidos, de acordo com o desenvolvimento do Plano de Ensino da disciplina, desenvolvido pela docente. Assim estas foram aplicadas nos meses de setembro a novembro de 2019, para as dez turmas pesquisadas.

\section{II.5 Coleta de dados e análise dos dados}

Foram aplicados ao longo da aplicação da SDI, no formato on-line, três questionários denominados: Perfil do aluno, Experiência de Ensino e Enquete Vocacional. O primeiro questionário teve o objetivo de identificação do perfil dos estudantes e dados cadastrais, o segundo esteve relacionado com a satisfação de uso dos recursos tecnológicos disponibilizados, por parte dos alunos e o terceiro buscou identificar áreas de interesse profissional dos estudantes e seu objetivo foi buscar perceber alguma tendência na área de interesse profissional. O questionário "Perfil do Aluno" foi composto por 14 perguntas fechadas, aplicadas on-line com o objetivo de saber quem são os alunos envolvidos na pesquisa.

O questionário "Experiência de Ensino" foi estruturado com 20 questões fechadas, e foi baseado em similar construído pela equipe de pesquisadores do RExLab da UFSC e amplamente usado e validado em outras pesquisas. Para o cálculo dos escores de satisfação, foi usada uma escala do tipo Likert de 5 pontos, formada por vários elementos sob forma de afirmações, sobre os quais deve ser expresso seu grau de satisfação, e para realizar a análise adotaram-se os seguintes valores em números: 1 discorda totalmente (DP), 2 discorda parcialmente (DP), 3 sem opinião (SO), 4 concorda parcialmente (CP), 5 concorda totalmente (CT). A escala de Likert é um método muito utilizado em pesquisas e foi desenvolvido por Rensis Likert em 1932. Conforme Silva Júnior e Costa (2014), é um método para mensurar atitudes no contexto das ciências comportamentais. A Tabela 2 apresenta a escala utilizada na pesquisa.

Tabela 2 - Escala tipo Likert utilizada na pesquisa.

\begin{tabular}{c|c|c|c|c}
\hline $\begin{array}{c}\text { Discordo } \\
\text { Totalmente } \\
\text { (DT) }\end{array}$ & $\begin{array}{c}\text { Discordo } \\
\text { Parcialmente } \\
\text { (DP) }\end{array}$ & $\begin{array}{c}\text { Sem Opinião } \\
\text { (SO) }\end{array}$ & $\begin{array}{c}\text { Concordo } \\
\text { Parcialmente } \\
(\mathrm{CP})\end{array}$ & $\begin{array}{c}\text { Concordo } \\
\text { Totalmente } \\
\text { (CT) }\end{array}$ \\
\hline 1 & 2 & 3 & 4 & 5 \\
\hline
\end{tabular}

Fonte: Autores (2020)

É muito importante poder avaliar se o instrumento utilizado na pesquisa consegue inferir ou medir aquilo a que realmente se propõe, conferindo relevância para a pesquisa (MATTHIENSEN, 2011). Para estimar a confiabilidade do questionário aplicado na pesquisa, 
foi utilizado o coeficiente alfa de Cronbach, a fim de, conferir maior relevância para a presente pesquisa. Este coeficiente foi apresentado por Lee J. Cronbach, em 1951.

O coeficiente alfa de Cronbach é uma medida de consistência interna que pressupõe que os itens (coletados a partir de uma escala de Likert, por exemplo) medem a mesma construção e estão altamente correlacionados entre si. São necessários pelo menos dois itens para estimar o valor do coeficiente alfa de Cronbach e quanto maior o número de itens, maior será a confiabilidade da escala. Todas as escalas de resposta que usam a escala Likert são politópicas, ou seja, elas têm mais de duas alternativas de resposta (BLAND; ALTMAN, 1997).

Os valores de alfa variam de 0 a 1,0; quanto mais próximo de 1 , maior é a consistência interna dos itens analisados. A confiabilidade da escala deve obter-se sempre com os dados de cada amostra para garantir a medida confiável do constructo na amostra concreta de investigação. Os autores George e Mallery (2003) recomendam, como critério geral, as seguintes indicações para avaliação dos coeficientes de alfa de Cronbach, conforme a Tabela 3.

Tabela 3 - Faixas definidas para interpretar os coeficientes do alfa de Cronbach.

\begin{tabular}{c|c}
\hline Faixas de alfa $(\alpha)$ & Magnitude \\
\hline Maior do que 0,90 & Excelente \\
\hline De 0,80 a 0,89 & Bom \\
\hline De 0,70 a 0,79 & Aceitável \\
\hline De 0,60 a 0,69 & Questionável \\
\hline De 0,50 a 0,59 & Pobre \\
\hline Menor do que 0,50 & Inaceitável \\
\hline
\end{tabular}

Fonte: Adaptado de George e Mallery (2003)

O terceiro questionário, denominado "Enquete Profissional" foi apenas um instrumento de autoconhecimento para buscar auxiliar o aluno a refletir sobre a sua escolha profissional. Foi utilizado como instrumento o questionário elaborado por Fabiano Fonseca da Silva, psicólogo do Serviço de Orientação Profissional da USP. O questionário indica as possíveis áreas de interesse e algumas sugestões de profissões que exigem o diploma de grau de bacharelado, porém, este tipo de teste não tem validade científica. Este questionário foi elaborado com 134 itens, divididos em 18 blocos, que formaram quatro grupos. O Quadro 3 apresenta uma visão resumida da enquete profissional. 
Quadro 3 - Resumo da enquete profissional.

\begin{tabular}{|c|l|c|c|l|}
\hline Grupo & \multicolumn{1}{|c|}{ Pergunta } & $\begin{array}{c}\mathrm{N}^{\mathrm{o}} \\
\text { Blocos }\end{array}$ & $\begin{array}{c}\mathrm{N}^{\mathrm{o}} \\
\text { Itens }\end{array}$ & \multicolumn{1}{|c|}{ Descrição } \\
\hline 1 & $\begin{array}{l}\text { Quais destas } \\
\text { atividades você faz ou } \\
\text { gostaria de fazer em } \\
\text { seu tempo livre? }\end{array}$ & 6 & 48 & $\begin{array}{l}\text { As atividades dedicadas ao lazer, pode mostrar } \\
\text { um forte indicativo quanto a uma possível } \\
\text { tendência de qual carreira profissional o aluno } \\
\text { queira seguir no futuro. }\end{array}$ \\
\hline 2 & $\begin{array}{l}\text { Quais os materiais ou } \\
\text { situações que mais } \\
\text { despertam o seu } \\
\text { interesse? }\end{array}$ & 3 & 24 & $\begin{array}{l}\text { A escolha no futuro de uma área do } \\
\text { conhecimento pode ter relação com a } \\
\text { curiosidade ou habilidade no manuseio de } \\
\text { materiais como, por exemplo, livros, } \\
\text { computadores, pincéis, rochas, ou a situações } \\
\text { como o cuidado com pessoas doentes, idosas. }\end{array}$ \\
\hline 3 & $\begin{array}{l}\text { Quais os ambientes } \\
\text { de trabalho que mais } \\
\text { lhe agradam? }\end{array}$ & 3 & 24 & $\begin{array}{l}\text { requentar lugares específicos ou desejar muito } \\
\text { conhecer outro local, pode indicar uma } \\
\text { tendência, no futuro, de querer um ramo de } \\
\text { trabalho voltado a isso. }\end{array}$ \\
\hline $\begin{array}{l}\text { Quais as profissões } \\
\text { que mais lhe atraem? }\end{array}$ & 6 & 48 & $\begin{array}{l}\text { O indicativo de algumas profissões pode revelar } \\
\text { ao aluno sua futura área de atuação, quer seja } \\
\text { nas áreas das Ciências Humanas, Engenharia e } \\
\text { Tecnologia dentre outras. }\end{array}$ \\
\hline
\end{tabular}

Fonte: Autores (2020).

\section{Resultados: Sequência Didática Investigativa}

A pesquisa foi realizada em duas escolas da rede pública estadual, no município de Criciúma em Santa Catarina: A Escola de Educação Básica Rubens de Arruda Ramos e a Escola de Educação Básica Joaquim Ramos. A aplicação das SDI e a coleta dos dados ocorreram no segundo semestre do ano letivo de 2019 com as turmas do Ensino Médio, nos três turnos letivos. Participaram da pesquisa 179 alunos, de 10 turmas, da disciplina de Física. Cabe destacar que as escolas não dispõem de laboratórios de Ciências, nem laboratórios de informática. O único espaço para realização de atividades práticas é a sala de aula.

\section{III.1 Sequências Didáticas Implementadas}

Foram construídas três sequências didáticas investigativas, que foram implementadas no AVEA, do Programa InTecEdu (https://https://rexlab.ufsc.br/intecedu/). A Fig. 4 apresenta exemplo de SDI implementada. Os temas estudados foram: $1^{\circ}$ ano: Queda Livre dos Corpos; $2^{\circ}$ ano: Calor e $3^{\circ}$ ano: Eletricidade. 

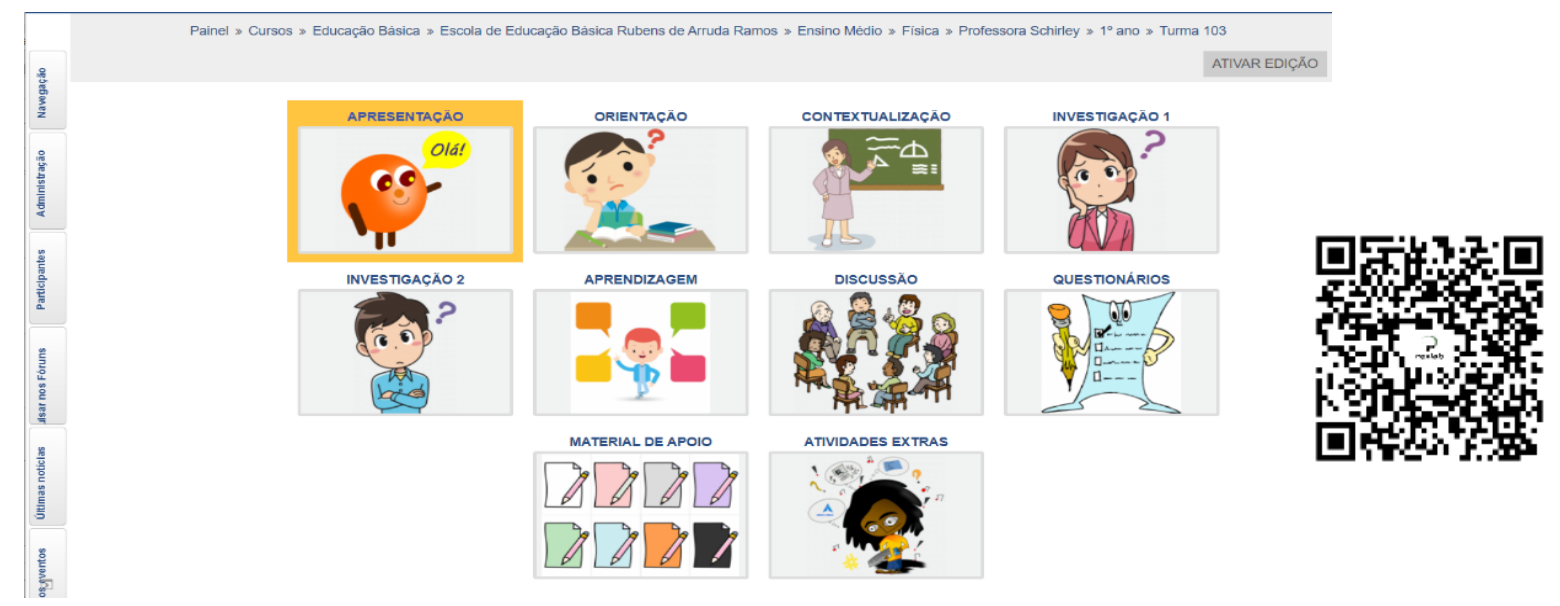

Fig. 4 - Exemplo do formato das Sequências Didáticas Propostas.

Fonte: <http://InTecEdu.ufsc.br/>.

A apresentação foi realizada em classe, e os alunos tomaram conhecimento do AVEA do Programa InTecEdu, também foram realizados os cadastros destes no ambiente virtual. Após o cadastramento dos alunos a professora apresentou as sequências didáticas e passou instruções sobre o manuseio do ambiente virtual.

A fase de orientação para as 10 turmas dos 3 anos foi estruturada a partir de vídeos que buscaram instigar em relação aos temas abordados. Assim, para o $1^{\circ}$ ano, foram disponibilizados três vídeos abordando o tem Queda Livre dos Corpos. Para o $2^{\circ}$ ano foi utilizado um vídeo sobre o tema Calor e o $3^{\circ}$ ano, cujo tema foi Eletricidade, foram três vídeos. Os vídeos tiveram o objetivo de estimular a curiosidade e motivá-los para estudar os temas propostos.

Para a fase de contextualização, foram propostas perguntas sobre o tema e também foi disponibilizado breve conteúdo teórico a respeito dos temas, para apoiar os estudos. Utilizou-se este expediente devido ao fato de ser uma metodologia aplicada pela primeira vez para os alunos, e assim, buscou-se ainda manter algum tipo de similaridade com a habitual deles. Para o $1^{\mathrm{o}}$ ano foram propostas quatro perguntas abertas sobre o tema queda livre, para o $2^{\circ}$ foram três perguntas para averiguar o entendimento deles sobre o tema Calor e para o $3^{\circ}$ ano três questões sobre o tema Eletricidade. Em relação aos conteúdos teóricos, estes foram disponibilizados de forma resumida no AVEA, e posteriormente foram abordados com mais detalhes em sala de aula. Num modelo de sala de aula invertida.

A interação real com os laboratórios on-line ocorreu na terceira fase, a investigação. Nesta fase, os alunos também coletaram dados específicos, a fim de, terem subsídios para responder às perguntas propostas. Os laboratórios on-line proporcionam a realização de experiências, não estando limitado ao tempo ou espaço.

Para a turma do $1^{\circ}$ ano, cujo tema estudado foi queda livre, foi utilizada a simulação on-line Movimento de Projétil, disponível na plataforma do Phet Colorado, para representar a queda livre de uma bola de canhão. $\mathrm{O}$ objetivo do uso desta simulação foi verificar o 
fenômeno da Queda Livre e demonstrar, por meio de cálculos, qual o tempo gasto pela bola ao cair no chão. Num primeiro momento, não foi considerada a resistência do ar.
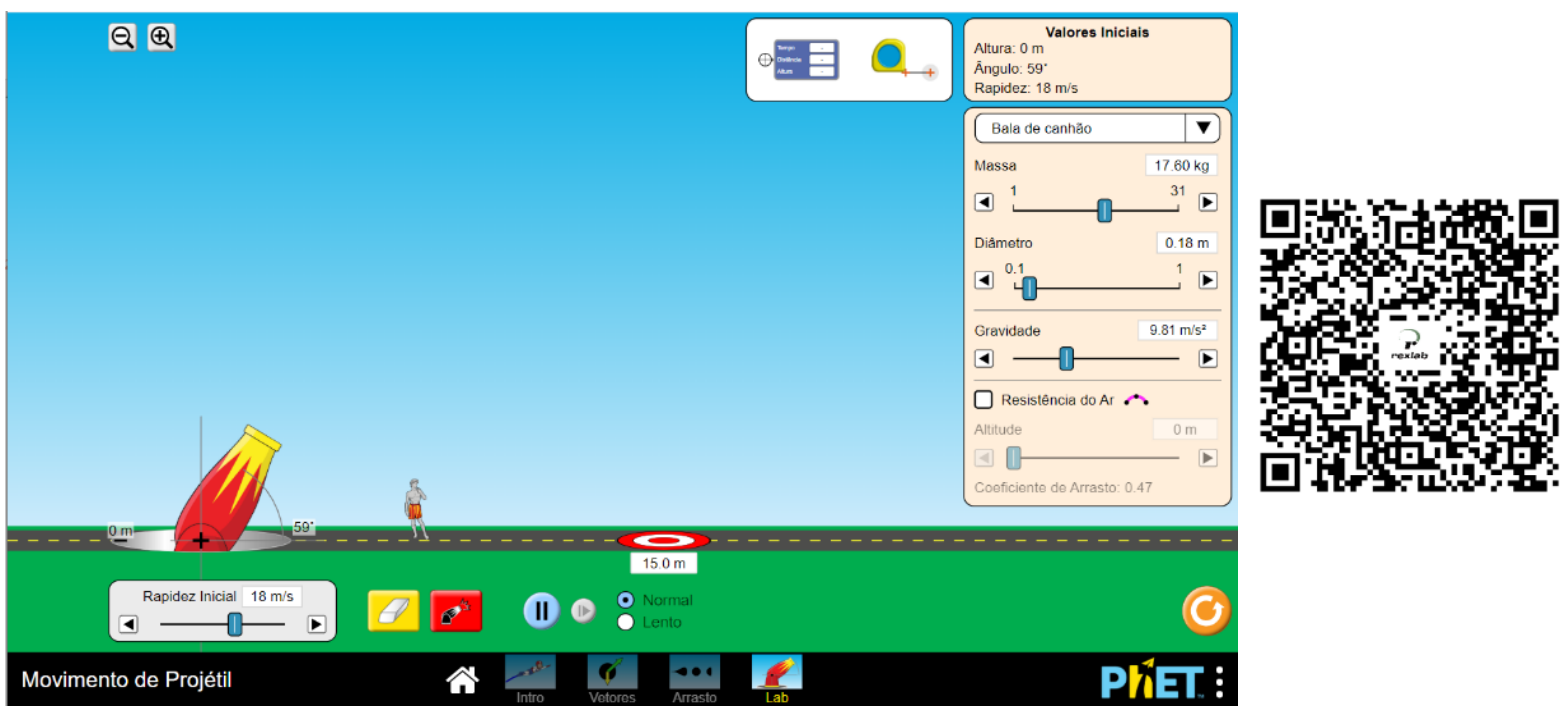

Fig. 5 - Laboratório Virtual, Movimento de projétil.

Fonte: $\quad<$ https://phet.colorado.edu/sims/html/projectile-motion/latest/projectilemotion_pt_BR.html>.

O passo seguinte foi utilizar um laboratório remoto (LR). O LR escolhido para utilização na SDI o Plano Inclinado, desenvolvido pelo RExLab e disponível na Plataforma RELLE.

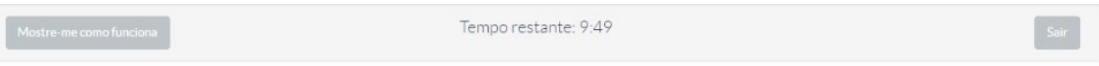

\section{Plano Inclinado}
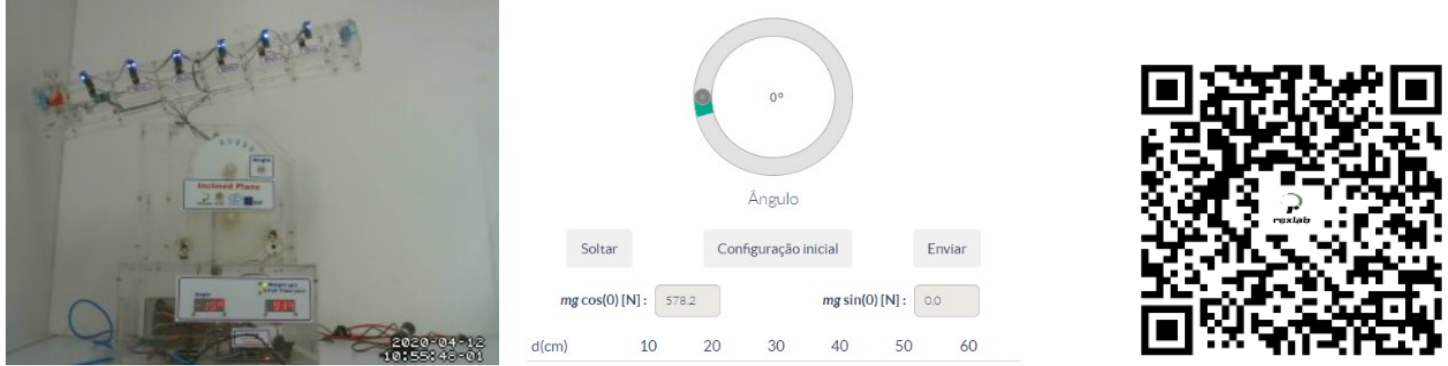

Fig. 6 - Laboratório Remoto, Plano Inclinado.

Fonte: <http://relle.ufsc.br/labs/7>. 
O LR Plano Inclinado dispõe de funcionalidade que possibilita a obtenção dos dados da experimentação realizada através do download de arquivo no formato $\mathrm{CSV}^{3}$. Foi solicitado que os alunos criassem uma tabela em planilha eletrônica ou manual, a fim de, comparar os dados obtidos na etapa teórica (cálculos) com os obtidos na simulação e no laboratório remoto.

Para realização das atividades práticas utilizando laboratórios on-line foi necessário disponibilizar tempo e recursos das escolas, uma vez que, alguns alunos não tinham disponibilidade de recursos computacionais. Assim, foram utilizados os computadores disponíveis nas Bibliotecas das escolas, uma vez que, a mesmas não dispõem de Laboratórios de Informática.

O tema abordado na turma do $2^{\circ}$ ano foi calor, para as atividades práticas foi escolhido o LR Condução de Calor em Barras Metálicas.

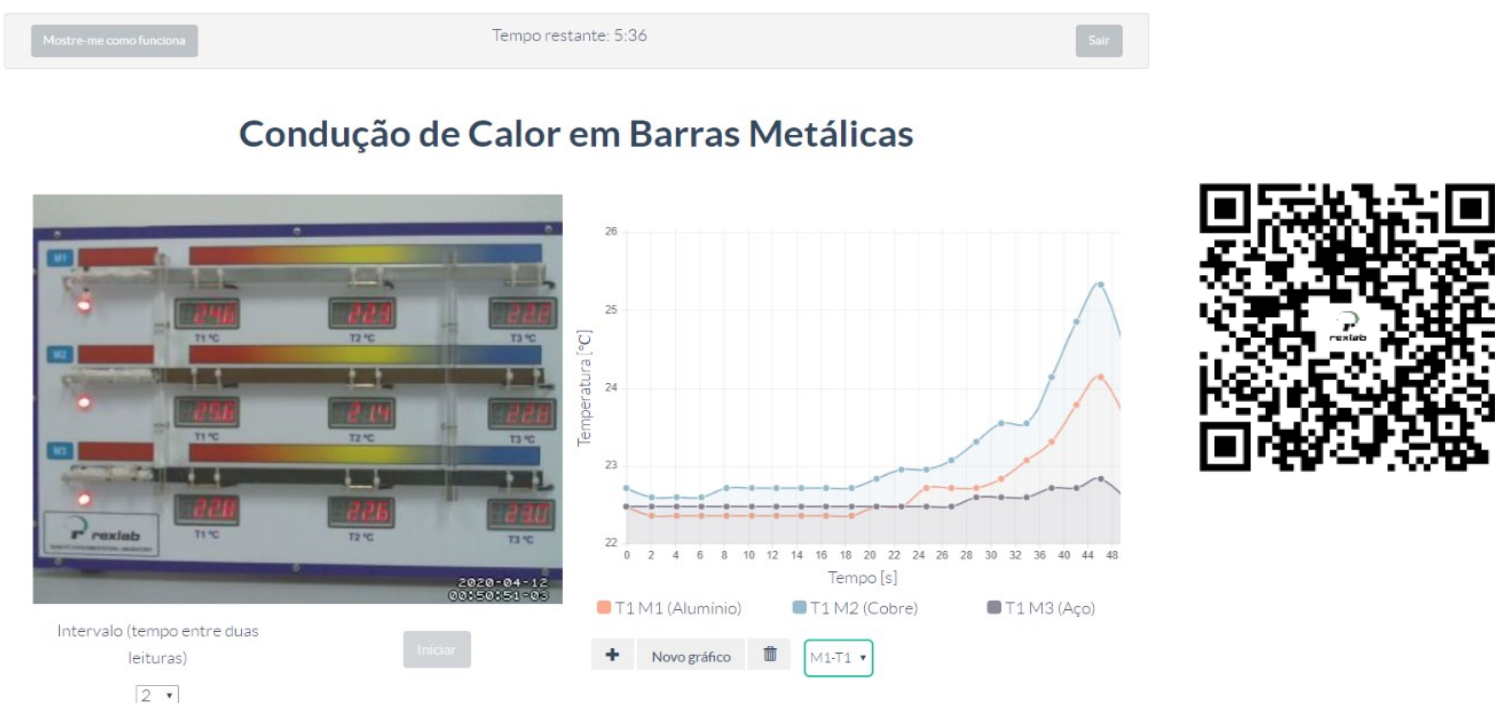

Fig. 7 - Laboratório Remoto, Condução de Calor em Barras Metálicas.

Fonte: <http://relle.ufsc.br/labs/13>.

A investigação para esta turma foi realizada em dois momentos, denominados investigação 1 e 2. A atividade no primeiro momento consistiu em acessar o LR e anotar as temperaturas das três barras (alumínio, cobre e aço), dispostas no experimento sem, contudo, acioná-lo. Uma vez que, o LR Condução de Calor em Barras Metálicas possui a funcionalidade de emissão de relatório da experimentação em formato PDF, os alunos também puderam gerar o relatório e salvá-lo. No segundo momento foi solicitado que os alunos efetuassem acesso ao LR com o objetivo de identificar em ordem crescente, as

\footnotetext{
3 Comma-separated values (ou CSV) é um formato de arquivo que armazena dados tabelados. Por ser bastante simples, arquivos .csv é um formato suportado por quase todas as planilhas eletrônicas e SGDB disponíveis no mercado.
} 
variações de temperatura em cada barra metálica, anotar qual dessas barras houve maior variação, pesquisar a condutividade térmica de cada material e comparar os valores da obtidos com os encontrados na literatura.

O tema abordado no $3^{\circ}$ ano foi eletricidade, mais especificamente associação de resistores. Para as atividades práticas foram escolhidos dois laboratórios remotos, um denominado Painel Elétrico CA, destinado ao estudo das associações em série, paralela e mista em redes de corrente alternada e outro Painel CC para o estudo das associações em série, paralela e mista em redes de corrente de contínua.

A fase de investigação foi realizada em dois momentos distintos chamados de investigação 1 e investigação 2. Na Investigação 1, os alunos acessaram o LR Painel Elétrico CA e realizaram executaram atividades tais como: abriram e fecharam as chaves para configurar as variações do circuito, observaram a diferença na intensidade da luminosidade das lâmpadas incandescentes e acompanharam a execução do experimento. A Figura 08 mostra LR Painel Elétrico CA.

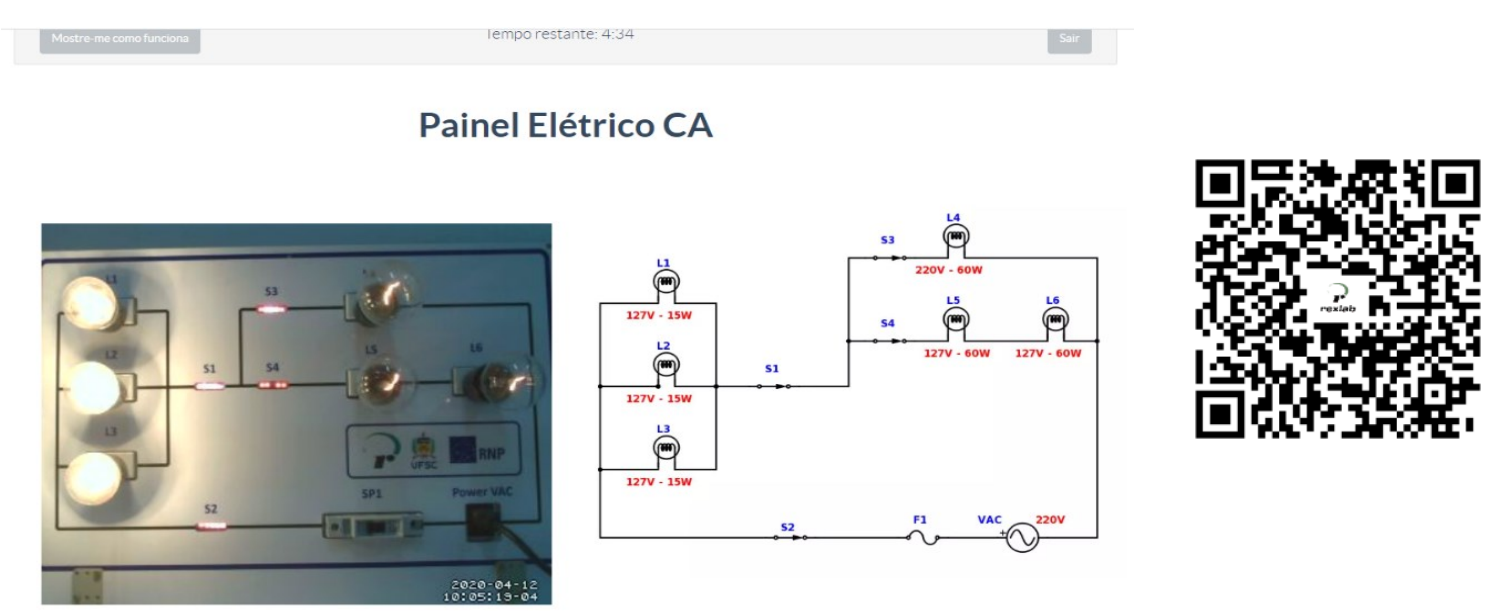

Fig. 8 - Laboratório Remoto, Painel CA.

Fonte: <http://relle.ufsc.br/labs/2>.

Na segunda etapa da investigação 2 os alunos acessaram o LR Painel Elétrico CC. A atividade prática consistiu em realizar a configuração de alguns circuitos pré-definidos e estudados em sala de aula. Assim, os alunos realizaram o acionamento das chaves para obtenção dos circuitos desejados, observaram o funcionamento e emitiram os relatórios, a fim de fazer estudo comparativo entre os dados obtidos junto ao LR e os valores calculados a partir das equações trabalhadas em sala de aula. A Fig. 9 mostra exemplo de circuito obtido no LR Painel Elétrico CC. 


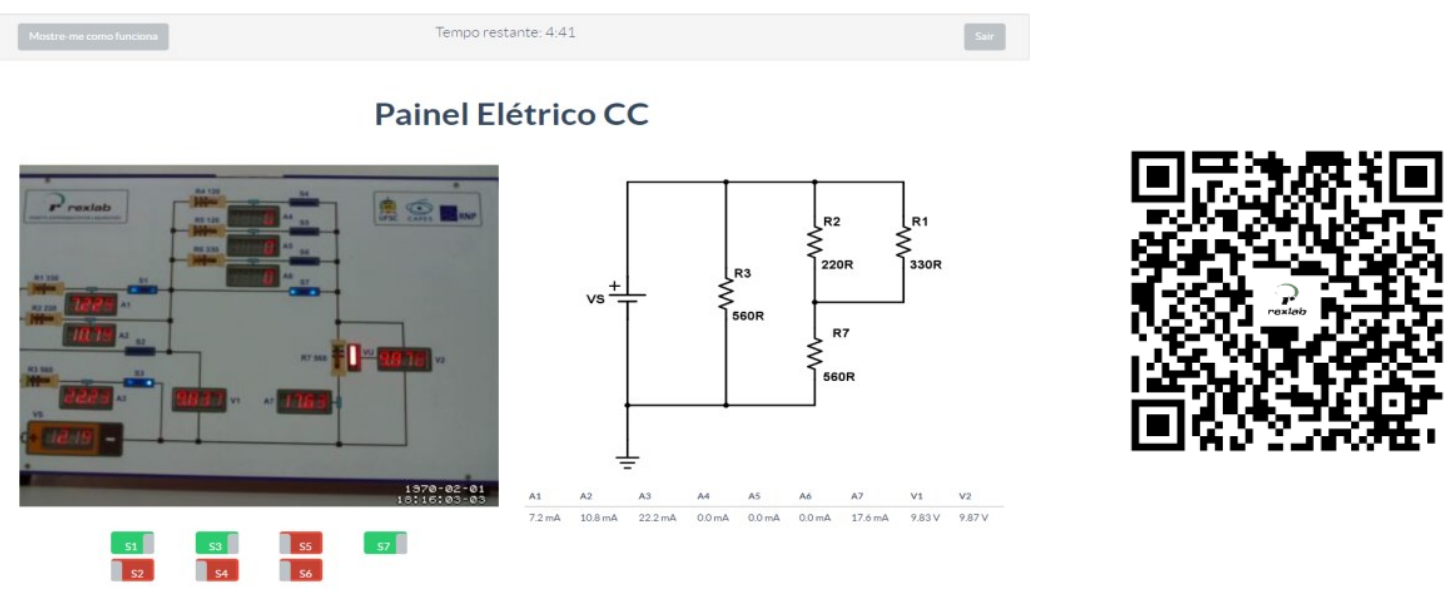

Fig. 9 - Laboratório Remoto, Painel CC.

Fonte: <http://relle.ufsc.br/labs/xx>.

$\mathrm{Na}$ fase denominada aprendizagem foi solicitado que os alunos realizassem atividades on-line, no AVEA, foram disponibilizadas tarefas para postagem posterior, e atividades on-line como questionários, entre outras. Estas tarefas e atividades on-line, realizadas em dois momentos, tiveram como objetivo a verificação e comprovação dos dados anteriormente coletados. Em relação ao $1^{\circ}$ ano, foram propostas duas atividades: na primeira os alunos acessaram o laboratório virtual movimento de projéteis, e verificaram o tempo de queda da esfera sem levar em consideração a resistência do ar e em seguida outra tentativa, desta vez habilitando o ícone da resistência do ar. Após, eles relataram suas observações em relação ao tempo de queda da esfera. No segundo, foi solicitado que construíssem uma tabela com os dados coletados da distância e tempo, da experimentação com o LR Plano Inclinado, além de construírem um gráfico de dispersão num editor de planilhas ou manualmente, mostrarem a linha de tendência formada em relação a velocidade encontrada; e analisarem o comportamento do gráfico e descrever se foi condizente com a literatura a respeito.

Para o $2^{\circ}$ Ano, a fase de aprendizagem foi composta por três atividades: na primeira foi solicitado que observassem o gráfico gerado no relatório fornecido pelo LR e respondessem a um questionário on-line composto por quatro questões abertas, para as quais os alunos tiveram que: a) anotar as novas temperaturas de cada barra, após a execução do experimento; b) calcular e anotar qual foi a variação de temperatura atingida das barras, após os dois minutos esperados; c) responder qual das três barras metálicas houve um maior aumento de temperatura e porque isso ocorreu e d) fazer a conversão da escala termométrica Celsius para a escala termométrica Fahrenheit das variações de temperaturas obtidas das três barras. A segunda atividade proposta foi um questionário com cinco questões, sendo uma pergunta aberta e quatro de múltipla escolha, elaboradas a partir de livros didáticos, sobre a conversão das escalas termométricas. Na terceira atividade os alunos elaboraram um breve relato condutividade térmica e postaram no AVEA. Esta atividade esteve relacionada à 
execução da experimentação remota, e nela os alunos tiveram que identificar em ordem crescente qual foi a variação de temperatura de cada barra; em qual destas barras houve maior variação de temperatura. De posse dos dados, os alunos pesquisaram sobre a condutividade térmica de cada barra metálica do experimento e, depois, compararam se os dados obtidos foram coerentes com a barra de maior variação.

Em relação ao $3^{\circ}$ ano, a fase de aprendizagem foi dividida em três momentos: o primeiro momento ocorreu após a prática com o laboratório remoto Painel Elétrico CA, no qual foi solicitado que os alunos postassem relato sobre o comportamento da luminosidade das lâmpadas em relação aos circuitos pré-estabelecidos, bem como resolvessem os cálculos solicitados sobre a resistência elétrica, tensão e intensidade da corrente elétrica. No segundo momento, foi realizada a postagem de exercício sobre o Painel Elétrico CC, referente a resolução de outros circuitos elétricos propostos. No terceiro momento, foram aplicados: uma atividade referente à associação de resistores (série, paralela ou mista) e um questionário, com dez questões, sendo três questões abertas e 07 sete questões fechadas sobre o tema cargas elétricas, ambas a serem respondidas no AVEA.

A fase da discussão teve como objetivo proporcionar aos alunos espaço onde pudessem vincular as perguntas e a abordagem teórica às evidências coletadas durante a fase de investigação. Nesta, estimulou-se a colaboração, a fim de, incentivar o grupo a refletir sobre seus processos e resultados de aprendizagem. Além disso, buscou-se avaliar os resultados de aprendizagem dos alunos. As atividades realizadas foram: produção de vídeos, participação em fórum e realização de questionários on-line. Atividades, estas, norteadas pelas questões propostas na fase de contextualização. Os vídeos foram produzidos pelos alunos, em grupos, e postados no AVEA. Os alunos foram orientados a produzirem os vídeos em seus dispositivos móveis. Posteriormente, os vídeos foram apresentados pelos grupos em sala de aula, onde cada grupo buscou responder as indagações efetuadas na fase de contextualização. Para extrapolar o debate iniciado na sala de aula, para fora da escola, foi utilizado o recurso Fórum do AVEA.

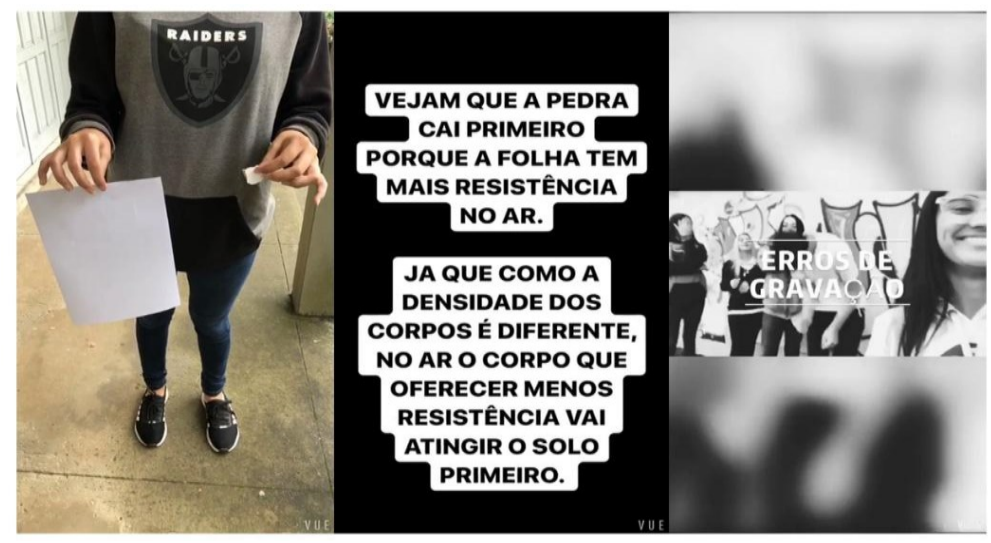

Fig. 10 - Exemplo de vídeo produzido pelos alunos.

Fonte: <https://intecedu.ufsc.br>. 
Além das fases para realização da SDI foram disponibilizados no AVEA os três questionários, referidos na seção de Metodologia, Perfil do Aluno, Experiência de Ensino e Enquete vocacional. Cujos resultados serão apresentados mais adiante.

Também, foi disponibilizado material de apoio abordando conceitos fundamentais de Física, na forma de apresentações de slides e guia de aplicação para os laboratórios remotos. Além, disso estavam à disposição no AVEA as chamadas "atividades extras", que não eram pontuadas, para fins de notas, e tinham sua realização livre, por parte dos alunos.

\section{Resultados e discussão dos questionários}

A seguir são apresentados os resultados obtidos, a partir da aplicação, dos seguintes questionários: Perfil do Aluno, Experiência de Ensino e Enquete vocacional.

\section{IV.1 Perfil dos estudantes}

O questionário aplicado teve por objetivo identificar o perfil dos estudantes e obter dados cadastrais, a partir do AVEA. Responderam ao questionário 179 alunos de 10 turmas do Ensino Médio, das duas escolas participantes da pesquisa. Destes, 51\% estudavam em turnos diurnos e $49 \%$ no noturno. A média de idade por faixa etária foi de 15,9 anos no $1^{\circ}$ ano, 17,1 anos no $2^{\circ}$ ano e 17,7 anos no $3^{\circ}$ ano. Assim, foi possível calcular uma taxa de distorção idade-série de $39,9 \%$, que é superior à média nacional de $28,2 \%$, indicada no Censo da Educação Básica 2018 (MEC/INEP, 2019).

O grupo apresentou 56\% alunos do sexo feminino e $46 \%$ masculino. Quando indagados se exercem atividades profissionais, dentre os entrevistados, 57,40\% declararam que sim, e 42,60\% declararam não.

Em relação à tecnologia, 52,7\% declararam que dispõem de computador pessoal nas suas residências. A taxa é considerada alta, se comparada com dados coletados pelo Centro Regional de Estudos para o Desenvolvimento da Sociedade da Informação - CETIC.br, o qual aponta que, no ano de 2018, apenas 19\% dos domicílios brasileiros possuíam computador em suas residências. Entre os entrevistados, $95,27 \%$ declararam que dispõem de acesso à internet. Porém, 88,76\% declarou que prefere o acesso por meio de dispositivos móveis. Segundo dados coletados do CETIC, 2018, ocorreu crescimento de usuários de internet no Brasil, entre os adolescentes na faixa etária de 9 a 17 anos, expandindo-se nos últimos 10 anos de $18 \%$ para $86 \%$, ou seja, percentual similar ao obtido na pesquisa.

Quando indagados sobre o local preferencial de acesso à internet, 87,57\% declararam que o local preferencial é a residência. $\mathrm{O}$ alto índice da preferência dos alunos pela residência demonstra que, mesmo alguns alunos que não possuem computador em casa, ainda assim optam por acessar os dispositivos móveis via domicílio. Também, entre os entrevistados $85,80 \%$ declararam que acessam a internet mais de uma vez por dia, sendo que $10,65 \%$ acessam pelo menos uma vez ao dia. Isso corresponde a dizer que $96,45 \%$ dos alunos acessam 
a internet de modo diário. Em relação às atividades mais realizadas quando do uso da internet, a utilização das redes sociais com 59,76\% foi a atividade mais acessada, seguida de $21,30 \%$ para assistir vídeos. Observa-se, pois, que o acesso dos estudantes à internet está vinculado em grande medida ao lazer.

Em relação à intenção dos estudantes em cursar algum curso de Ensino Superior, entre os entrevistados, $86,39 \%$ declararam que pretendem cursar, sendo que $13,61 \%$ responderam não ter tal intenção. Já em relação às indicações dos estudantes para possíveis áreas para cursar o Ensino Superior, observou-se que 10,65\% dos entrevistados declararam preferências para cursos nas áreas das engenharias e 23,67\% na área da saúde. Outros $28,40 \%$ não têm definição de que curso pretendem cursar. A área das Ciências Exatas (Matemática, Física, Química e Biologia) ficou em apenas 2,96\%, o que leva a uma reflexão sobre a necessidade da mudança de postura quanto ao que ensinar, e como, especificamente, neste caso, quando à disciplina de Física.

\section{IV.2 Questionário Experiência de Ensino}

O questionário "experiência de ensino" buscou avaliar a utilização dos recursos disponibilizados, por parte dos alunos, mediante fatores tais como: usabilidade, percepção de aprendizagem, satisfação e utilidade. Responderam ao questionário 179 alunos.

Para facilitar a análise dos resultados, foi realizado e estabelecido o Escore Médio (EMd) para as respostas obtidas no questionário, a partir escala tipo Likert de 5 pontos. Para verificação se as atitudes foram positivas ou negativas, através do EMd, foram atribuídas as seguintes condições: valores inferiores a 3 representaram atitudes desfavoráveis e maiores que 3 favoráveis, enquanto que o valor 3 foi considerado "indiferente" ou "sem opinião".

O EMd obtido para os 20 itens do questionário foi de 4,51, demonstrando uma atitude muito positiva dos alunos em relação a utilização dos recursos tecnológicos utilizados, a saber o AVEA e os laboratórios remotos. O Desvio Padrão calculado para as respostas obtidas foi de 0,104 . O desvio padrão é uma medida que expressa o grau de dispersão de um conjunto de dados. Ele indica o quanto um conjunto de dados é uniforme e quanto mais próximo de 0 for o desvio padrão, mais homogêneo são os dados. $\mathrm{O}$ valor obtido permite inferir que os conjuntos de dados avaliados apresenta característica homogênea. O Coeficiente de Variação do Desvio Padrão apurado foi de 2,30\%. Este coeficiente é usado para expressar a variabilidade dos dados estatísticos excluindo a influência da ordem de grandeza da variável. Para fins interpretação é valido dizer que se o valor obtido for menor ou igual a $15 \%$, considera-se baixa dispersão, ou seja, os dados são homogêneos, para valores entre 15 e $30 \%$, considera-se a dispersão média dispersão e se os valores foram maiores que que $30 \%$, considera-se alta dispersão e que os dados são heterogêneos. O valor percentual obtido permite considerar que o conjunto de dados avaliados apresenta baixa dispersão.

Para fins de validação do questionário, na totalidade de suas questões, foi aplicado o coeficiente de consistência interna alfa de Cronbach. O valor obtido para o questionário 
aplicado, em sua totalidade (20) questões, foi de 0,93. Valor considerado por George e Mallery (2003), como excelente, de acordo com a Tabela 03. A Figura 11 mostra os valores percentuais dos 20 itens, agrupados para DF + D (Discordo Fortemente + Discordo), SO (Sem Opinião) e CF + C (Concordo Fortemente + Concordo).

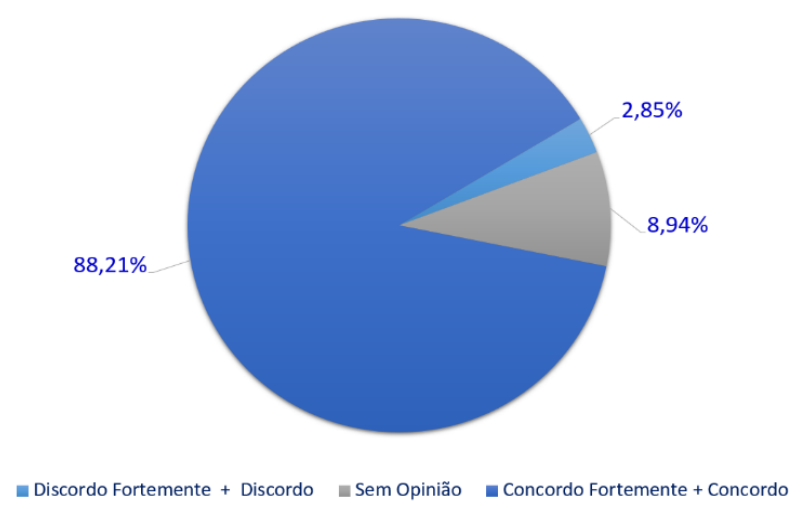

Fig. 11 - Valores agrupados para $D F+D$ e $C F+C$.

Fonte: Autores (2020).

A Fig. 12 apresenta o escore médio de Likert para cada um dos 20 itens analisados. $\mathrm{O}$ item de menor escore foi o $\mathrm{n}^{\mathrm{o}} 5$ (A distância entre os estudantes e o laboratório remoto estimula a reflexão dos estudantes, pois, é preciso concentrar-se mais na realização do experimento para a verificação das informações) com 4,28 e o maior o $n^{\circ} 13$ (Desenvolver e disponibilizar novos laboratórios é importantes, visto que estes auxiliam nos processos de ensino e de aprendizagem), com 4,66. A uniformidade do conjunto de dados obtidos e a dispersão muito baixa, certamente estão relacionadas a fatores como a novidade dos recursos utilizados, o fato das escolas não possuírem laboratórios de ciências, entre outros.

Devido ao escore médio muito próximo dos itens, não serão apresentados na totalidade os itens. A seguir são relacionados os que obtiveram $C F+C$, superiores a $90 \%$ :

- A flexibilidade de acesso é um ponto positivo, pois você pode acessar a qualquer hora de qualquer local $92 \%$;

- Possibilidade e oportunidade de reforçar o conhecimento teórico 91\%;

- Amplia as experiências de sala aula, pois incrementa as atividades práticas $91 \%$;

- O uso da experimentação remota para a prática de ensino de física agrega qualidade ao estudo $93 \%$;

- O uso da experimentação remota para a prática de ensino de física contribuiu para aprendizagem $94 \%$;

- É uma importante estratégia educacional que integra recursos tecnológicos, ensino aprendizagem e construção do conhecimento 91\%;

- Desenvolver e disponibilizar novos experimentos são importantes, visto que estes auxiliam no processo de ensino aprendizagem $94 \%$. 


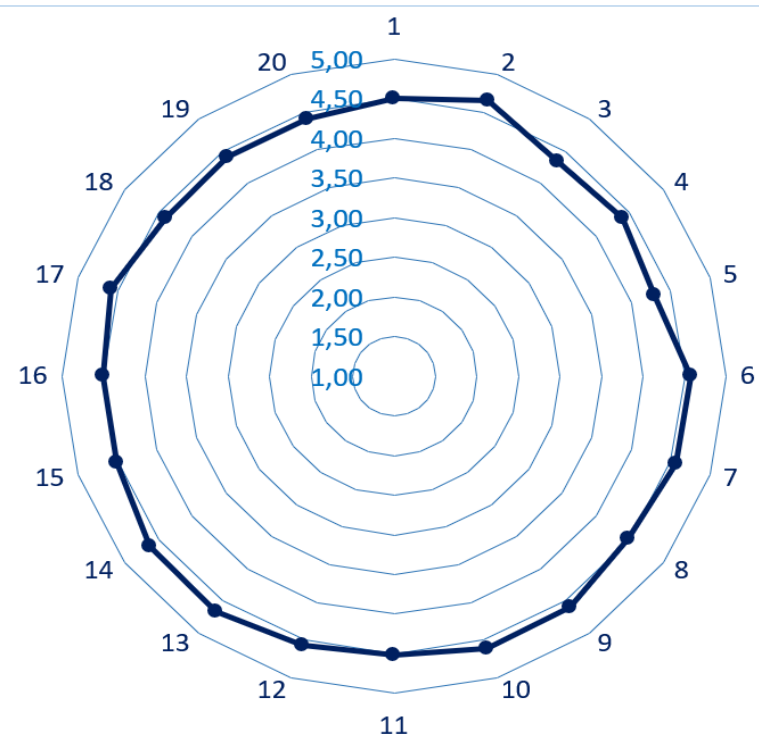

Fig. 12 - EMd para os 20 itens analisados.

Fonte: Autores (2020).

Pensamos que os resultados acima apresentados respondem à primeira questão de pesquisa proposta: Como os alunos percebem o uso dos laboratórios on-line na disciplina de Física?

\section{IV.3 Enquete Vocacional}

Responderam à enquete 179 alunos, assim distribuídos: 58 alunos do $1^{\circ}$ ano, 56 do $2^{\circ}$ ano e 65 do $3^{\circ}$ ano. A contagem dos pontos foi efetuada a partir da soma dos escores obtidos nos quadros por grupos e categorizados de acordo com as áreas do conhecimento. A Fig. 13 apresenta a totalização dos grupos para os alunos matriculados na disciplina de Física nos três anos do Ensino Médio. O maior escore obtido foi para Ciências da Vida (748), seguido de Profissões de Ajuda (629), Artes (625), Engenharia e Tecnologia (601), Ciências Humanas e Sociais (471), Comunicação (464), Ciências Exatas (452) e Negócios (408).

A segunda questão de pesquisa proposta foi assim redigida: Os estudantes das turmas pesquisadas seguem os dados apresentados, em nível nacional, e não demonstram interesse pelas áreas científicas e tecnológicas?

É possível afirmar a partir dos dados obtidos no questionário Perfil do Aluno e na Enquete profissional, que a afirmativa é correta, ou seja, os alunos não demonstram interesse pelas áreas científicas e tecnológicas. No questionário Perfil do Aluno, 86,39\% declararam que pretendem cursar o Ensino Superior, porém, 10,65\% dos entrevistados declararam preferências para cursos nas áreas das engenharias e 23,67\% na área da saúde. Já em relação à área das Ciências Exatas (Matemática, Física, Química e Biologia) apenas 2,96\% declaram intenção em cursar. Na Enquete Profissional, os cursos da área de Engenharia e Tecnologia foram a $4^{\mathrm{a}}$ opção com maior pontuação e Ciências Exatas a $7^{\mathrm{a}}$ para um total de 8 
possibilidades.



Fig. 13 - Escores por área do conhecimento.

Fonte: Autores (2020).

\section{Considerações finais}

Este documento teve como objetivo apresentar um estudo de caso sobre a utilização de laboratórios on-line, para atividades práticas em disciplina de Física no Ensino Médio, em duas escolas da rede pública. Foram pesquisadas neste documento respostas para as duas perguntas de pesquisa propostas. A primeira foi buscar entender como os alunos perceberam o uso dos laboratórios on-line na disciplina de Física. A segunda, se os estudantes das turmas pesquisadas seguem a tendência dos dados apresentados, em nível nacional, demonstrando desinteresse pelas áreas científicas e tecnológicas.

Para responder a primeira indagação vamos nos basear nos dados do questionário Experiência de Ensino, que foi respondido pela totalidade dos alunos. O escore médio de Likert, obtido para os 20 itens do questionário foi de 4,51, demonstrando uma atitude muito positiva dos alunos em relação a utilização dos recursos tecnológicos utilizados, a saber o AVEA e os laboratórios remotos. Agrupando os valores percentuais dos 20 itens, em DF + D (Discordo Fortemente + Discordo), SO (Sem Opinião) e CF + C (Concordo Fortemente + Concordo). Obteve-se DF $+\mathrm{D}=8,94 \%$ e $\mathrm{CF}+\mathrm{C}=88,21 \%$. Ou seja, um nível de concordância muito alto em relação à experiência obtida pelo uso dos laboratórios remotos e do AVEA. Estes resultados permitem-nos refletir sobre o potencial das tecnologias digitais e seu potencial de contribuição para a educação.

A segunda indagação esteve relacionada a falta de interesse da população jovem pelas áreas das ciências, engenharias e matemática. Trata-se de uma preocupação em nível mundial, inclusive foi manifestada pela UNESCO e outras instituições. Assim, percebeu-se, a partir dos dados obtidos no questionário Perfil do Aluno e na Enquete profissional, que os alunos participantes não demonstraram interesse pelas áreas científicas e tecnológicas. No questionário Perfil do Aluno, 86,39\% declararam que pretendem cursar o Ensino Superior, 
porém, $10,65 \%$ dos entrevistados declararam preferências para cursos nas áreas das engenharias e 23,67\% na área da saúde. Já em relação à área das Ciências Exatas (Matemática, Física, Química e Biologia), apenas 2,96\% declaram intenção em cursar. No instrumento Enquete Profissional, os cursos da área de Engenharia e Tecnologia foram a $4^{\mathrm{a}}$ opção com maior pontuação e Ciências Exatas a $7^{\mathrm{a}}$ para um total de 8 possibilidades.

Os resultados dos questionários aplicados mostraram aprovação dos alunos em relação aos recursos tecnológicos utilizados na experiência didática, por outro lado, a manifestação de adesão com carreiras associadas às áreas de ciências, tecnologia, engenharia e matemática foi muito baixa. Os motivos que levam os jovens a não se motivarem pelas disciplinas e carreiras nestas áreas são diversos, e passam pela impopularidade das disciplinas STEM e pela carência de infraestrutura para realização de atividades práticas, entre outros. Porém, a necessidade de disponibilizar ambientes mais atrativos para o ensino e a aprendizagem mostra-se como uma necessidade. Pois, as tecnologias digitais evoluem numa velocidade vertiginosa e são parte integrante da sociedade em que vivemos e que impactam no modo de vida das pessoas, principalmente das crianças, adolescentes e jovens. Logo, a inserção destas tecnologias, no contexto educacional, permite redesenhar a educação criando novas e interessantes oportunidades de ensino e de aprendizagem. Por exemplo, promover o acesso a novas ferramentas no ensino de Física, ampliará a motivação dos estudantes para esta disciplina e, quem sabe, melhorará as possibilidades de adesão de estudantes a carreiras vinculadas às áreas científicas e tecnológicas. Já os laboratórios on-line permitem estender não só a sala de aula, como também a escola, uma vez que não limitam estes processos ao tempo e ao espaço da sala de aula.

\section{Referências bibliográficas}

AAPT. Goals of the Introductory Physics Laboratory. American Journal of Physics. 66, 483 485 (1998). Disponível em:

$<$ https://www.uv.es/fsicadoc/laboratoris_grau_fisica/Goalsphyslabs.pdf $>$. Acesso em: 02 ago. 2020.

ARANHA, M. L. A. História de educação. 2. ed. São Paulo: Editora Moderna, 1996. 255 p.

BLAND, J. M.; ALTMAN, D. G. Statistics notes: Cronbach's alpha. The British Medical Journal, [s.1.], v. 314, n. 7080, p.572-572, 22 fev. 1997. BMJ. Disponível em: $<$ http://dx.doi.org/10.1136/bmj.314.7080.572>. Acesso em: 05 jun. 2020.

BOHUS, C.; CROW, L. A.; AKTAN, B.; SHOR, M. H. Running Control Engineering Experiments Over the Internet. Technical Report. Oregon State University, Corvallis, OR, USA, 1996.

BRASIL. Instituto Nacional de Estudos e Pesquisas Educacionais Anísio Teixeira (INEP). 
Censo da Educação Superior 2018: notas estatísticas. Brasília, 2019. Disponível em: $<$ http://download.inep.gov.br/educacao_superior/censo_superior/documentos/2019/censo_da_ educacao_superior_2018-notas_estatisticas.pdf>. Acesso em: 01 ago. 2020.

BRASIL. Instituto Nacional de Estudos e Pesquisas Educacionais Anísio Teixeira (INEP). Censo Escolar 2018. Brasília, 2019. Disponível em:

$<$ http://portal.inep.gov.br/web/guest/resultados-e-resumos>. Acesso em: 12 nov. 2019.

CARNEGIE MELLON UNIVERSITY. The Virtual Lab: Engineering the Future. Disponível em: <http://www.ece.cmu.edu/ stancil/virtual-lab/virtual-lab.html>. Acesso em: 27 set. 2019.

CGI.br/NIC.br Centro Regional de Estudos para o Desenvolvimento da Sociedade da Informação (Cetic.br), Pesquisa sobre o Uso das Tecnologias de Informação e Comunicação nos domicílios brasileiros - TIC Domicílios 2018.

CORREIA, R. F. C. M. Modelo de Evolução dos Laboratórios Remotos e Virtuais. 2018. 261f. Tese (Doutorado em Engenharia Eletrotécnica e de Computadores) - Universidade Nova de Lisboa, Lisboa, Portugal.

DE JONG, T.; SOTIRIOU, S.; GILLET, D. Innovations in STEM education: The Go-Lab federation of on-line labs. Smart Learning Environments, v. 1, n. 3, p. 1-16, 2014.

GALÁN, D.; FABREGAS, E.; GARCIA, G.; SÁENZ, J.; DORMIDO-CANTO, S.; DORMIDO, S. Online Virtual Control Laboratory of Mobile Robots. IFAC-PapersOnLine, v. 51, Issue 4, 2018, p. 316-321. Disponível em:

$<$ http://www.sciencedirect.com/science/article/pii/S240589631830380X>. Acesso em: 12 set. 2019.

GEORGE, D.; MALLERY, P. SPSS for Windows step by step: A Simple Guide and Reference, 11.0 Update. Boston: Allyn and Bacon, 2003. 386 p.

GRIMUS, M.; EBNER, M. Mobile Learnin and STEM: First Experiences in a Senior High School in Ghana. In: CROMPTON, H.; TRAXLER, J. (Org.) Mobile Learning and STEM: case studies in practice. Nova York: Routledge, 2016.

HODSON, D. Assessment of practical work. Some considerations in philosophy of science. Science and Education, v. 1, n. 2, p. 115-144, 1992. 
LORO, F. Evaluación y Aprendizaje en Laboratorios Remotos: Propuesta de un Sistema Automático de Evaluación Formativa Aplicado al Laboratorio Remoto VISIR. 2018. 405p. Tese (Doutorado em Tecnologías Industriales) - Escuela Técnica Superior de Ingenieros Industriales, Universidad Nacional de Educación a Distancia (UNED), Madrid. Disponível em: <http:/e- spacio.uned.es/fez/view/tesisuned:ED-Pg-TecInd-Fgarcia>. Acesso em: 18 dez. 2019.

MARTIN-HANSEN, L. Examining ways to meaningfully support students in STEM. IJ STEM. Ed 5, 53, 2018. Disponível em: <https://doi.org/10.1186/s40594-018-0150-3>. Acesso em: 01 mar. 2020.

MATTHIENSEN, A. O uso do coeficiente alfa de Cronbach em avaliações por questionários. Boa Vista: Embrapa Roraima, 2011.

MINNER, D. D., LEVY, A. J., CENTURY, J. (2010). Inquiry-based science instruction what is it and does it matter? Results from a research synthesis years 1984 to 2002. Journal of Research in Science Teaching, v. 47, p. 474496. Doi:10.1002/tea.20347.

MUJKANOVIC, A. Impact of students' preferences on the design of on-line laboratories. In: GLOBAL ENGINEERING EDUCATION CONFERENCE (EDUCON), IEEE, 2015. p. 823826. Disponível em: <https://doi.org/10.1109/EDUCON.2015.7096067>. Acesso em: 10 jan. 2020.

NAFALSKI, A.; MACHOTKA, J.; NEDIC, Z. Collaborative Remote Laboratory NetLab for Experiments in Electrical Engineering. Using Remote Labs in Education: Two Little Ducks in Remote Experimentation, 2011.p. 177-199.

NMC - NEW MEDIA CONSORTIUM. Laboratórios Remotos e Virtuais. 2018. Disponível em: $<$ https://www.nmc.org/horizon_topic/virtual-and-remote- laboratories/laboratoriosremotos-e-virtuais/>. Acesso em: 10 jan. 2020.

OECD. Education at a Glance 2018: OECD Indicators, OECD Publishing, Paris. Disponível em: <https://doi.org/10.1787/eag-2018-en>. Acesso em: 22 jul. 2020.

PEDASTE, M.; MÄEOTS, M.; SIIMAN, L. A.; DE JONG T.; VAN RIESEN, S. A.N.; KAMP, E.T.; MANOLI, C. C.; ZACHARIA, Z. C. Phases of inquiry-based learning: Definitions and the inquiry cycle. Educational Research Review, v. 14, p. 47-61, 2015. Disponível em: <https://doi.org/10.1016/j.edurev.2015.02.003>. Acesso em: 08 ago. 2020. 
SILVA JÚNIOR, S. D.; COSTA, F. J. Mensuração e Escalas de Verificação: uma Análise Comparativa das Escalas de Likert e Phrase Completion. Revista Brasileira de Pesquisas de Marketing, Opinião e Mídia, v. 15, p. 1-16, 2014.

SILVA, J. B.; BILESSIMO, S. M. S.; ALVES, J. B. M. Integração de Tecnologias na Educação: Práticas inovadoras na Educação Básica. Araranguá: Hard Tech Informática Ltda, 2018a. 110 p. Disponível em: <https://publicacoes.RExLab.ufsc.br/>. Acesso em: 18 jan. 2020 .

SILVA, J. B.; OLIVEIRA, G.; SILVA, I. N.; MAFRA, P. M.; BILESSIMO, S. M. S. Block.ino: Remote Lab for Programming Teaching and Learning. International Journal Of Advanced Engineering Research And Science, [s.1.], v. 7, n. 1, p. 41-47, 2020. AI Publications. Disponível em: <http://dx.doi.org/10.22161/ijaers.71.6>. Acesso em: 11 jan. 2020.

TAMIR, P. Content analysis focusing on inquiry. Journal of Curriculum Studies, v. 17, n. $1, \mathrm{p} 87-94,1985$.

WELLINGTON, J. "Practical work in science: Time for a reappraisal". In: WELLINGTON, J. (Ed.). Practical work in school science: Which way now? Londres: Routledge. 1998. p. 315 .

WORLD ECONOMIC FORUM. The Human Capital Report 2016. World Economic Forum 2016. Disponível em <https://www.weforum.org/reports/the-global-human-capital-report2016>. Acesso em: 05 jul. 2020.

WORLD ECONOMIC FORUM. The Global Competitiveness Report 2013-2014. World Economic Forum 2013. Disponível em:

$<$ http://www3.weforum.org/docs/WEF_GlobalCompetitivenessReport_2013-14.pdf $>$. Acesso em: 12 jul. 2020.

ZUTIN, D. G.; AUER, M. E.; MAIER, C.; NIEDERSTÄTTER, M. Lab2go - A repository to locate educational on-line laboratories. In: IEEE EDUCON, 2010. p.1741-1746.

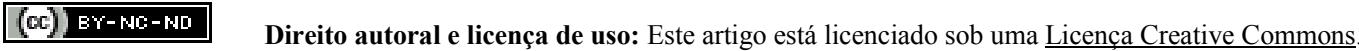

